\title{
Affective polarization in multiparty systems
}

\author{
Markus Wagner ${ }^{\dagger}$
}

\begin{abstract}
Affective polarization captures the extent to which citizens feel sympathy towards partisan in-groups and antagonism towards partisan out-groups. This is comparatively easy to assess in two-party systems, but capturing the pattern of affect towards multiple parties is more complex in multiparty systems. This paper first discusses these challenges and then presents different ways of measuring individuallevel affective polarization using like-dislike scores, a widespread measure of party sympathy. Using data for 51 countries and 166 elections from five modules of the Comparative Study of Electoral Systems, I then show that affective polarization adds to existing concepts as a way of understanding political participation and democratic orientations. Studying affective polarization outside the US could therefore have important consequences for our understanding of citizen perceptions of politics as well as citizen behaviour, but we need the appropriate measures to do so.
\end{abstract}

Keywords: Affective polarization; ideological polarization; negative partisanship; partisanship

${ }^{\dagger}$ Department of Government, University of Vienna, Rathaussstrasse 19/1/9, $1010 \mathrm{Vi}$ enna, Austria; markus.wagner@univie.ac.at. 


\section{Introduction}

Since Campbell et al. (1960), the study of partisanship has been recognized as a key determinant of political attitudes and behaviour, making party identification one of the most well-established theories in research on elections and voting (Johnston 2006). In much of this research, partisanship has generally been considered a type of social identity (Greene 1999, 2004; Huddy 2001), with partisans holding a strong in-group affect towards the party they favour and identify with (Brewer and Brown 1998). ${ }^{1}$

Yet, in recent work scholars have argued that to understand partisanship and its consequences fully we also need to take into account out-group affect, i.e. how negatively voters feel about competitors (Iyengar, Sood and Lelkes 2012; Iyengar et al. 2019). Of course, this was already recognized by Campbell et al. (1960: pp.121f.), who argued (emphasis added): "the political party serves as the group toward which the individual may develop an identification, positive or negative, of some degree of intensity'. ${ }^{2}$ In this recent revival of interest in negative partisanship, Iyengar, Sood and Lelkes (2012) and Hetherington and Rudolph (2015) show that the key change in partisan affect in the United States over the past 50 years has been that American voters who identify with either the Republicans or the Democrats have become more negative in their attitudes towards the other party, moving from moderate levels of sympathy towards increasingly strong dislike. Other, related research has emphasised the importance of negative partisanship for understanding voter attitudes and behaviour (Medeiros and Noël 2014; Mayer 2017; Rose and Mishler 1998). To capture the extent to which citizens hold both positive ingroup affect and negative out-group affect towards parties, researchers have coined the term 'affective polarization' (Iyengar, Sood and Lelkes 2012; Lelkes 2016). In extremer cases, we can also speak of 'partisan prejudice' and 'interparty hostility' among partisans (Lelkes 2016; Lelkes and Westwood 2017).

\footnotetext{
${ }^{1}$ An alternative view of partisanship as a running tally of evaluations was put forward by Fiorina (1981).

${ }^{2}$ This point had also been made by other earlier research (e.g. Garry 2007; Maggiotto and Piereson 1977; Richardson 1991), but had largely been ignored by the discipline. Perhaps the increasing ideological polarization in the United States led to this renewed interest in negative out-group feelings among researchers.
} 
However, the concept of affective polarization has so far mainly been applied to what is arguably the most straightforward case: the American two-party system. Given the prominence of this concept in recent analyses of American electoral and party politics, it is not surprising that there have been a number of recent attempts to apply this concept to other countries. Important examples are Westwood et al. (2018), Ward and Tavits (2019), Reiljan (2019) and Gidron, Adams and Horne (2018). This research has shown that affective polarization is widespread outside the United States, is not a simple byproduct of ideological polarization and alters perceptions of party competition.

However, apart from Reiljan (2019), these papers do not engage extensively with the conceptual issues that arise from moving to multiparty settings. Yet, analyzing affective polarization multiparty systems is more demanding simply because polarization is no longer between one in-party and one out-party, with polarization the affective distance between the two. Applying the concept to multi-party systems therefore means that we need to be more specific about our understanding of affective polarization. To address this challenges, this paper makes two recommendations concerning how affective polarization should be conceptualized and measured in multiparty systems.

First, affective polarization in multiparty settings should be defined and assessed as as the extent to which politics is seen as divided into two distinct camps, each of which may consist of one or more parties. This approach is consistent with prior evidence that multiple positive identification is possible and widespread in multi-party systems (Weisberg 1980; Garry 2007). In the US context, research on affective polarization generally assumed the existence of positive in-group towards a single party, but this is not appropriate for multiparty contexts, especially when examining the polarization of affect towards various groups.

Second, the size of parties matters for levels of affective polarization. Hence, a citizen's perception of the political system is more affectively polarized if they feel negatively towards a large competitor than if they dislike a minor party. For example, in Germany, negative feelings towards the Alternative for Germany (AfD) matter less than negative feelings towards the Christian Democrats. Similary, affective polarization in Germany 
should increase if the AfD doubles its vote share (holding the voter's negative feelings towards the party stable). Thus, overall measures of affective polarization need to be weighted by party size.

Building on this understanding of affective polarization, I then propose a measurement approach for affective polarization at the individual level and distinguish it from other approaches. It allows researchers to measure affective polarization for non-partisans and partisans alike, unlike the measure proposed in Reiljan (2019). I implement this in 51 countries and in 166 elections using data from the Comparative Study of Electoral Systems. As pointed out by Druckman and Levendusky (2019) and Iyengar et al. (2019), such scores do not capture the full range of meanings of affective polarization. However, given their widespread availability, like-dislike scores are a suitable place to start to engage in cross-national comparisons of affective polarization (see also Reiljan 2019; Ward and Tavits 2019; Gidron, Adams and Horne 2018; Boxell, Gentzkow and Shapiro 2020). The measurement of affective polarization presented here is based on like-dislike scores.Descriptive evidence from this data shows that affective polarization in the US is average in international comparison, confirming findings in Westwood et al. (2018) and Gidron, Adams and Horne (2019).

I then examine how affective polarization is associated with partisanship, ideological polarization, democratic values and participation. These assocations are examined for four different measurement approaches. The key finding here is that, while the overall conclusions remain the same, associations with other variables do differ in appreciable ways depending on which measurement approach we choose.

These analyses also demonstrate that individuals' level of affective polarization differs theoretically and empirically from partisanship and from ideological polarization. Moreover, affective polarization is associated cross-nationally with democratic beliefs and political participation in ways that go beyond partisanship and ideological polarization. Hence, in addition to presenting a conceptualisation and measurement approach for affective polarization in multiparty systems, this paper shows how affective polarization can add to our understanding of political attitudes and behaviour in ways that go beyond 
existing concepts such as partisanship and ideological polarization.

\section{Partisanship and affective polarization}

Affective polarization builds on the research portraying partisanship as a social identity (Greene 1999, 2004; Huddy, Mason and Aarøe 2015; Iyengar et al. 2019). Partisan ties are often generated during early adulthood and often remain largely fixed over the life course, leading to substantial stability in electoral decisions (Niemi and Jennings 1991; Shively 1979; Dinas 2014a,b). Moreover, party identification does more than just determine our vote choice: it helps to shape how citizens develop attitudes and engage with politics (Campbell et al. 1960; Carsey and Layman 2006; Johnston 2006). Positive affect towards one's favoured party is the first component of affective polarization.

The second component of affective polarization is negative affect towards other parties and their supporters. In terms of social identity, this is the extent to which other parties and partisans are seen as 'out-groups' (Greene 1999; Brewer and Brown 1998). Beyond the relatively binary concept of (positive) partisanship, individuals arguably have some level of positive or negative affect towards all parties they know about (Richardson 1991). However, 'out-group derogation' is not an essential counterpart to 'in-group favouritism' (Greene 2004; Brewer and Brown 1998). Hence, as already pointed out by Weisberg (1980), Richardson (1991) and Maggiotto and Piereson (1977), individuals, including strong partisans, can vary quite extensively in the extent to which they hold negative views of opposing parties and their supporters. In accordance with the focus on attitudes towards out-groups, scholars have also argued that there is 'negative partisanship' as well as positive partisanship (Medeiros and Noël 2014; Abramowitz and Webster 2016).

In a two-party system such as the United States, affective polarization is captured by the extent to which voters feel (a) positive in-group affect towards a party and its supporters and (b) negative out-group affect towards the other party and its supporters. Overall, affective polarization then captures the extent to which a voter has an 'us-versusthem' perception of the party system.

Affective polarization is both an aggregate-level and individual-level phenomenon. There are thus two meanings of affective polarization, which should not be conflated: 
(a) each individual has a level of in- and out-group affect that may be polarized or not (individual-level affective polarization); and (b) each political system has an average level of such patterns of in- and out-group feelings (aggregate-level affective polarization). Aggregate-level affective polarization is simply an averaged version of individual-level affective polarizition. In general, the term 'affective polarization' is used more to describe aggregate-level than individual-level patterns (Reiljan 2019).

In this paper, I focus more on affective polarization at the individual level, so whether an individual's pattern of affect towards parties is polarized or not. A parallel measure is the perceived level of ideological polarization: voters differ in whether they see the parties in the system as ideologically similar or ideologically distant.

\section{Affective polarization in multiparty systems}

There is little doubt that affective polarization matters outside the Unites States. Research by Westwood et al. (2018), which examines levels of trust between partisans in the UK, Belgium and Spain, provides important evidence that affective polarization is just as important in many countries outside of the US and also has a greater impact than social cleavages. Using experimental data, Helbling and Jungkunz (2019) also show that partisan identities form the basis of social divides in Germany and Austria. Gidron, Adams and Horne (2019) present cross-country evidence that affective polarization in the US is by no means unusually high (see also Boxell, Gentzkow and Shapiro 2020). Using CSES data, Ward and Tavits (2019) show that affective polarization shapes citizen perceptions of political competition and party systems. Finally, Reiljan (2019) shows evidence of widespread hostility to out-partisans in Europe.

Yet, this research tends not to reflect specifically on the challenges of moving to a multiparty setting. Doing so raises important questions concerning the conceptualization and measurement of affective polarization. To be a useful description of how an individual relates to political parties in the party system, a conceptualisation and measure of affective polarization in multiparty systems should summarize the configuration of feelings towards political parties (and their supporters). In doing so, it needs to go beyond the binary measures of positive and negative partisanship: these only measure the party 
that voters feel closest to and the one that they dislike most (Medeiros and Noël 2014; Abramowitz and Webster 2016; Mayer 2017). As we will see, applying the concept of affective polarization to multiparty systems requires us to be more specific in how we understand partisan identities.

Two configurations of feelings towards parties are easy to assess by applying existing conceptions of affective polarization to multiparty systems. First, affective polarization is low if a citizen has the same level of affect towards all parties and partisans. This is the case if a citizen dislikes all parties, likes all parties, or is indifferent about all parties. Politically disaffected voters who feel negatively towards parties in general are therefore not affectively polarized (Klar, Krupnikov and Ryan 2018).

Second, affective polarization is high if a citizen likes one party and dislikes all others. This is the classic pattern expected by traditional accounts of partisanship as a social identity. In this view, feelings of closeness towards parties are mutually exclusive as they represent competing identities, so voters are unlikely to feel close to more than one party at once.

One option for assessing affective polarization in multiparty systems would be to proceed with such a strong conceptualization of partisanship as a social identity. This would mean assuming that only one party can be the 'in-group'. Affective polarization measures in multiparty systems should then capture the extent the single in-group is seen positively compared to the out-group, i.e. all other parties (Reiljan 2019).

However, the difficulty of measuring affective polarization in multiparty systems arises from the fact that many citizens feel positive towards two or more parties, while disliking others. Empirical research shows that positive affect towards parties is indeed often not confined to one party. For instance, research on partisanship in multiparty systems shows that multiple identificaton appears to be possible (Weisberg 1980; Garry 2007). Hence, people can have more than one positive party identification (Garry 2007). Hence, citizens may exhibit clear polarization in terms of their affect, but without positive affect being exclusive to one party. Such patterns may be quite frequent in larger party systems such as Sweden or Finland, where parties form distinct ideological camps or blocs. 
In addition, party identification is by some accounts a declining phenomenon in many countries (Dalton 2002). However, this development is accompanied by the rise of parties that elicit quite strong negative affect, both on the radical right (e.g. Germany, Sweden, Denmark) or on the radical left (e.g. Greece, Spain). The emergence of such parties is not necessarily accompanied by strong in-group feelings. This means that affective polarization can also increase absent positive affect, a dynamic that is less well-captured by existing measures, at least conceptually.

Hence, a better approach to assesing affective polarization should be based on the spread of positive and negative affect (see also Ward and Tavits 2019). Using such an approach, affective polarization would also be high for the citizen who feels strong positive affect towards two parties and negative affect towards their competitors. This more expansive definition of affective polarization thus covers situations where citizens perceive there to be two general camps, which may each be made up of one or several parties.

A separate question is whether affective polarization should be weighted by the size and therefore relevance of parties. Arguably, it matters more if the liked and disliked parties are very large competitors than if a voter happens to dislike a small party. This is because size and importance are often strongly correlated: larger parties are more important for the party system and government formation. The key to understanding the affective configuration of party systems is arguably whether the larger parties within that system are affectively distant or close. Curini and Hino (2012) similarly justify weighting their left-right polarization scores.

Weighting is sensible from both a cross-sectional and a dynamic perspective. Crosssectionally, imagine a system with two large parties and one smaller one, akin to the UK in the early 2000s with Labour, the Conservatives and the Liberal Democrats. Now take a voter who likes two of these parties and dislikes a third. A voter's affective polarization would arguably be more severe if the disliked party was Labour rather than the Liberal Democrats.

From a dynamic, over-time perspective, we would also want affective polarization 
to vary over time depending on the size of each party. Take the example of a strongly disliked party that increases in size, for instance a voter who strongly dislikes an emerging radical-right party. If this party doubles in popularity, then this dislike is more relevant for understanding party competition and should be reflected in measures of affective polarization. Hence, if we want to capture a society's affective polarization, introducing weights into our measures may be helpful.

We now turn towards operationalizing this approach with survey data.

\section{Measuring affective polarization in multiparty systems}

To measure affective polarization, we need to capture the extent to which individuals feel positively towards one or more parties and negatively towards other parties. Ideally, this measurement would relate to political identities and would not refer directly to ideological or socio-demographic aspects. So far, there is no single agreed way of measuring affective polarization, but various approaches have been suggested. For example, affective polarization has been measured directly using attitudes towards having one's child marry a supporter of the party and using questions assessing stereotypes about out-partisans (Iyengar, Sood and Lelkes 2012). It has also been measured indirectly using implicit attitude tests, trust games and dicator games (Iyengar and Westwood 2015; Westwood et al. 2018; Iyengar et al. 2019).

Instead of these approaches, I measure affect towards parties using the standard likedislike question included in election surveys; for a similar approach see Reiljan (2019), Gidron, Adams and Horne (2019) or Ward and Tavits (2019). Using the extent to which citizens like (or feel warmly towards) some parties and dislike (or feel coldly towards) other parties has been used to measure affective polarization by several groups of researchers (Iyengar, Sood and Lelkes 2012; Rogowski and Sutherland 2016; Abramowitz and Webster 2016; Lelkes, Sood and Iyengar 2017).

The key advantage of using feeling or like-dislike scores is their broad availability: few other questions concerning affective reactions to parties have been asked systematically in surveys. These questions also tap into the essence of affective polarization, namely an overall positive or negative reaction to parties as a whole. 
What like-dislike scores do not capture is affect towards fellow or opposing partisans rather than parties (Druckman and Levendusky 2019). This is better measured using other approaches (e.g., Iyengar and Westwood 2015; Iyengar, Sood and Lelkes 2012). Hence, using like-dislike scores of parties tells us less than other measures about affective polarization as a manifestation of social identities. Moreover, the general nature of likedislike scores means that it is inherently open to individuals what they use to provide assessments - e.g., identities, ideology or simple affect (Lelkes 2016, 2019) - even if some authors argue that feeling thermometers primarily measure affective responses (Marcus 1988; Marcus, Neuman and MacKuen 2000). These shortcomings should not prevent us from examining affective polarization using this existing measure, especially given recent evidence that different measures of affective polarization tend to correlate strongly (Druckman and Levendusky 2019). ${ }^{3}$

\section{Measurement approach: spread of like-dislike scores}

Given the preceding discussion, I suggest that affective polarization should be measured as the spread of like-dislike scores for each respondent. This approach recognizes that individuals can feel positively towards more than one party. An individual with low affective polarization then has similar levels of affect for all parties, be it positive or negative. In contrast, an individual with high affective polarization has very different levels of affect for the different parties. This measure of affective polarization is based directly on existing measures of perceived ideological polarization, which also see polarization as the spread of the positions parties are seen as having (Dalton 2008; Ezrow 2007). It is also how Huddy, Bankert and Davies (2018) implicitly assess affective polarization in Sweden: they look at polarization in partisan affect between the two large coalitions of parties. It is also how Ward and Tavits (2019) essentially measure affective polarization.

Measuring affective polarization as the spread of like-dislike scores is simple: it is the average absolute party like-dislike difference relative to each respondent's average party

\footnotetext{
${ }^{3}$ Note that like-dislike scores also suffer from differential item functioning: in the words of Lelkes (2016: p.401), 'for some, a warm glow envelops all groups; for others, the world is a much chillier place'. The measures presented below avoid this problem to a certain extent by focusing on differences in scores rather than absolute levels.
} 
like-dislike score. More formally, it is:

$$
\text { Spread }_{i}=\sqrt{\frac{\sum_{p=1}^{P}\left(\text { like }_{i p}-\overline{\operatorname{like}_{i}}\right)^{2}}{n_{p}}}
$$

$p$ is the party, $i$ the individual respondent and $l i k e_{i p}$ the like-dislike score assigned to each party $p$ by individual i.

However, it may make sense to weight polarization scores by parties' vote shares. In addition to the substantive justification presented above, there is also the more practial reason that surveys often vary in how many smaller parties are included in like-dislike question batteries. By weighting smaller parties less, these inevitable distortions weigh less heavily on affective polarization scores.

Hence, we can also calculate affective polarization as the weighted average party affect difference compared to each respondent's weighted average party affect. The precise formula for affective polarization is adapted from Alvarez and Nagler (2004) and Ezrow (2007) for party system left-right dispersion (see also Curini and Hino 2012). The Weighted Affective Polarization (WAP) equation for parties $\mathrm{j}$ and voter $\mathrm{i}$ is:

$$
\text { Spread }_{i}=\sqrt{\Sigma_{p=1}^{P} v_{p}\left(\text { like }_{i p}-\overline{\text { like }_{i}}\right)^{2}}
$$

$v_{p}$ is the vote share share of each party, measured as a proportion with a range from to 0 to 1 . The mean affect should itself be weighted by party size and is calculated as:

$$
\overline{\operatorname{like}}_{i}=\Sigma_{p=1}^{P}\left(v_{p} * l i k e_{i p}\right)
$$

Note that affective polarization is calculated for all respondents who declare a level of affect for at least two parties, even if more parties were asked about in the survey.

An example calculation of affective polarization scores for nine ideal-typical voters is shown in Table 1. The aim of these examples is to show how the measures behave in different scenarios and that the measures have face validity. The scenario used is based on a simple party system with two large parties, parties A and B, and two small parties, 
parties C and party D. The vote shares are normalized so that they sum to 100. 
Table 1: Example calculation of affective polarization in a four-party system

\begin{tabular}{|c|c|c|c|c|c|c|c|c|c|}
\hline Voter & 1 & 2 & 3 & 4 & 5 & 6 & 7 & 8 & 9 \\
\hline Party & $\begin{array}{l}\text { Positive } \\
\text { ID, large } \\
\text { party }\end{array}$ & $\begin{array}{l}\text { Positive } \\
\text { ID, small } \\
\text { party }\end{array}$ & $\begin{array}{l}\text { Positive } \\
\text { ID, large } \\
\text { and small } \\
\text { party }\end{array}$ & $\begin{array}{l}\text { Positive } \\
\text { ID, large } \\
\text { parties }\end{array}$ & $\begin{array}{l}\text { Dislikes } \\
\text { small } \\
\text { party }\end{array}$ & $\begin{array}{l}\text { Dislikes } \\
\text { large party }\end{array}$ & $\begin{array}{l}\text { No posit- } \\
\text { ive affect }\end{array}$ & $\begin{array}{l}\text { No negat- } \\
\text { ive affect }\end{array}$ & Indifference \\
\hline Party A (40\%) & 10 & 0 & 10 & 10 & 10 & 10 & 5 & 10 & 4 \\
\hline Party B $(30 \%)$ & 0 & 0 & 0 & 9 & 5 & 0 & 0 & 5 & 4 \\
\hline Party C (15\%) & 0 & 0 & 0 & 0 & 0 & 5 & 0 & 5 & 3 \\
\hline Party D (15\%) & 0 & 10 & 9 & 0 & 5 & 5 & 0 & 5 & 3 \\
\hline \multicolumn{10}{|l|}{ Spread of scores } \\
\hline Unweighted & 4.33 & 4.33 & 4.76 & 4.76 & 3.54 & 3.54 & 2.17 & 2.17 & 0.50 \\
\hline Weighted & 4.90 & 3.57 & 4.85 & 4.41 & 3.49 & 4.15 & 2.45 & 2.45 & 0.46 \\
\hline \multicolumn{10}{|l|}{ Mean distance } \\
\hline Unweighted & 10.00 & 10.00 & 8.19 & 8.19 & 7.07 & 7.07 & 5.00 & 5.00 & 0.82 \\
\hline Weighted & 10.00 & 10.00 & 8.67 & 7.11 & 6.61 & 7.91 & 5.00 & 5.00 & 0.71 \\
\hline
\end{tabular}


The first two voters are ideal-typical party identifiers who support one party and dislike all others. The first and second voters differ in the size of the party they identify with. For the unweighted measures, this does not change the result. However, the weighted measure does differ for the two voters, as the first voter shows up as having a greater level of affective polarization in the weighted version. This reflects that the first voter supports a large party, so the party system is more evenly divided into two camps for the first voter. So, the weighted spread-of-scores measures also depends on whether voter sympathies create two similarly-sized camps. Arguably, affective polarization is indeed higher if the one's own group is confronted by an out-group of similar size.

The third and fourth voters each have one 'in-party' but also have strong positive affect for another party. We can see that affective polarization for these two cases is similar to that for voters 1 and 2 . Note that the unweighted score is higher because voters view the party system as divided into two more equally-sized camps. The weighted score is higher for voter 3 than for voter 4 because voter 3 strongly dislikes one of the two large parties, creating a more equal division of affect across parties.

The next two voter profiles show what happens if the most-disliked party is small or large. Voter 5, who dislikes only a small party, has lower weighted affective polarization than voter 6, who dislikes a larger party. Their unweighted affective polarization is naturally the same. Note that, with the weighted measure, voter 6 has a larger value than voter 2 . This makes sense when considering that voter 6 has strong positive affect for the largest party and strong negative affect for the second-largest party, so has large affective distance for the key players. In contrast, voter 2 is closer to a voter who simply dislikes all players apart from a smallish party.

The final three voter profiles show scenarios where there is less affective polarization. Voter 7 has no positive affect, voter 8 no negative affect. Both have the same affective polarization scores as the spread of affect in the system is the same. These voters' level of affective polarization is also clearly lower than those for the first four voters, who exhibit clear affective polarization. Voter 9 is largely indifferent between the four parties and has very low affective polarization as a result. 
Overall, we can see that affective polarization using the spread-of-scores measures is high when voters have strong affect for one or more parties. Affective polarization with the weighted measure is also higher if voter sympathies and antipathies are equally divided across the party system. Conversely, the spread-of-scores measures produces low polarization for indifference or low variation. Finally, the unweighted score is naturally not responsive to the size of parties that are liked or disliked, creating a less dynamic and responsive measure.

\section{Comparison measure: Mean distance from the most-liked party}

As noted above, a second, more restrictive way of conceiving of affective polarization is as the average affective distance of other parties from one's most liked party. This 'mean-distance' measure captures how much lower on average an individual's affect for other parties is. Hence, this measure assumes positive identification with one party as the key aspect of affect patterns. It is worth formalizing this measure and comparing it to the spread-of-scores measure.

The mean-distance measure can be calculated as:

$$
\text { Distance }_{i}=\sqrt{\frac{\sum_{p=1}^{P}\left(\text { like }_{i p}-\text { like }_{\max , i}\right)^{2}}{n_{p}}}
$$

This time, $n$ is the number of parties without the most-liked party. $l i k e_{\max }$ is the the score assigned to the most-liked party. Again, we can also calculate a weighted version of this measure. This would then take into account that it should matter more if an individual strongly dislikes large parties rather than a small, insignificant competitor. This is calculated as:

$$
\text { Distance }_{i}=\sqrt{\Sigma_{p=1}^{P} v_{p}\left(l i k e_{i p}-l i k e_{\max , i}\right)^{2}}
$$

The mean-distance measure differs from the spread-of-scores measure in that the former captures how much an individual on average dislikes other parties compared to his or her favoured party, while the latter simply captures the extent to which affect is 
spread out across the various options.

The example in Table 1 highlights this difference. Voters 3 and 4 have lower levels of affective polarization than voters 1 and 2 using the mean-distance measure, while they have similar levels using the spread-of-scores measure. Given that voters 3 and 4 are also strongly affectively polarized, this example shows the limitations of using a mean-distance measure. However, it is worth noting that the two measures behave very similarly if we consider scenarios where voters favour one party, so the relative patterns for voters 5 to 9 are very similar for both measures.

In sum, the spread-of-scores measures is superior if we want a measure that captures the empirical reality of affect patterns in multiparty systems better than the meandistance measure. The spread-of-scores measure better captures opposition between blocs of parties rather than between single parties. The measure is also theoretically better suited to voters without a single positive party identification. For such voters, it does not make sense to presuppose a social identity constructed around parties, but they may nevertheless hold positive and negative feelings towards certain parties. The spread-ofscores measure is therefore more applicable to multiparty systems that are based more around ideologies and coalitions rather than around single parties.

However, the mean-distance measure could be the preferred approach if researchers are more interested in exclusive partisan identities, so the extent to which one's preferred party is seen as the only 'good' party. For this purpose, it could potentially also be restricted to those expressing a partisan identity (Reiljan 2019). Moreover, it is worth noting that the two measures behave similarly if voters tend to only have one favoured 'in-party' or have no 'in-party' at all.

\section{Comparison with other proposed measures}

These measures are naturally related to other attempts to use like-dislike scores to assess affective polarization. Here, I will briefly distinguish how these approaches relate to the two measures discussed above.

First, Ward and Tavits (2019) use the simple standard deviation of like-dislike scores in their work on how affective polarization shapes perceptions of politics in multiparty 
systems. This measure is closely related to the unweighted spread-of-scores measure.

Second, Gidron, Adams and Horne (2018) and Reiljan (2019) both use like-dislike for partisans only, measuring the weighted mean like-dislike score for out-parties. The measure by Reiljan (2019) also takes into account how much a partisan likes their own party. These measures are closely related to the mean-distance measure, but limit measurement to self-declared partisans. Potential measurement error in the party identification question would appear to counsel against this restriction. In addition, the possibility of multiple positive identities mean that the spread-of-scores measure may be preferable for theoretical reasons.

Finally, Gidron, Adams and Horne (2019) consider the affective distance between the main centre-left and the main centre-right party. This measure is hard to relate to the two measures presented above. However, the measure in Gidron, Adams and Horne (2019) serves the useful purpose of comparing non-US systems to US levels of affective polarization.

\section{Data and descriptives}

The dataset used is the Comparative Study of Electoral Systems. This project has included like-dislike questions in all rounds since the start of the project in 1996. Modules 1 to 4 are used, along with the advance release of Module 5; excluding countries with a Polity IV score below 8, this leaves us with 166 surveys and 51 countries. In the first round of the CSES surveys, voters could place up to six parties, where applicable; in the later modules, this was increased to a total of nine possible placements. ${ }^{4}$

The precise question wording for the like-dislike question is: 'I'd like to know what you think about each of our political parties. After I read the name of a political party, please rate it on a scale from 0 to 10 , where 0 means you strongly dislike that party and 10 means that you strongly like that party. If I come to a party you haven't heard of or you feel you do not know enough about, just say so. The first party is PARTY A.' This is

\footnotetext{
${ }^{4}$ As a robustness check, an analysis of Module 4 results was conducted using only the first four like-dislike scores. The correlation between these the reduced and the longer measure was high $(r=0.97)$ for the weighted spread-of-scores measure, so analysts can feasibly rely on surveys with less extensive like-dislike batteries.
} 
followed by questions about the other parties. The question text has remained the same in all four modules. 'Don't know' responses are treated as missing throughout this paper.

In the following, I focus on the weighted spread-of-scores measure of affective polarization, but compare results to the unweighted measure and to the weighted and unweighed mean-distance measures. ${ }^{5}$

First, Figure 1 shows the average level of affective polarization for the countries included the CSES project. If there are several CSES surveys for a country, respondents are pooled for this analysis. We can see that affective polarization is particular high for less wealthy, perhaps also less stable democracies: Montenegro, Kenia and Albania, for instance.

This graph also shows that, empirically, how we measure affective polarization is less consequential than the ideal-typical scenarios shown in Table 1 would indicate. Differences in the relative ordering depending on which measure we use are small. It is consistent with this finding that the bivariate correlation between the different measures is always high, at around 0.9 or above. Appendix A.1 shows that the correlation between the measures is also high irrespective of party system size. Differences between the two measures depend much more on the distance between the most-liked party and the second-most-liked party (Appendix A.1).

This Figure also shows that the United States has average levels of affective polarization in international comparison. This is surprising, both because the US has been the overwhelming focus of research and because partisanship is often argued to be less intense in many other democracies. However, these findings are consistent with those presented in Gidron, Adams and Horne (2019) and Boxell, Gentzkow and Shapiro (2020). However, Appendix A.8 shows that the United States has a higher relative level of affective polarization if we focus on those with a party identification. Hence, partisans and non-partisans in the US differ more strongly than elsewehere their strength of affective polarization.

\footnotetext{
${ }^{5}$ The vote shares used to weight party affect are taken from the election of the CSES survey, which means they are very close approximates of the current electoral strength of each party. Lower house vote shares are taken if available; if not, upper house or presidential election vote shares are used.
} 
Figure 1: Mean levels of affective polarization by country

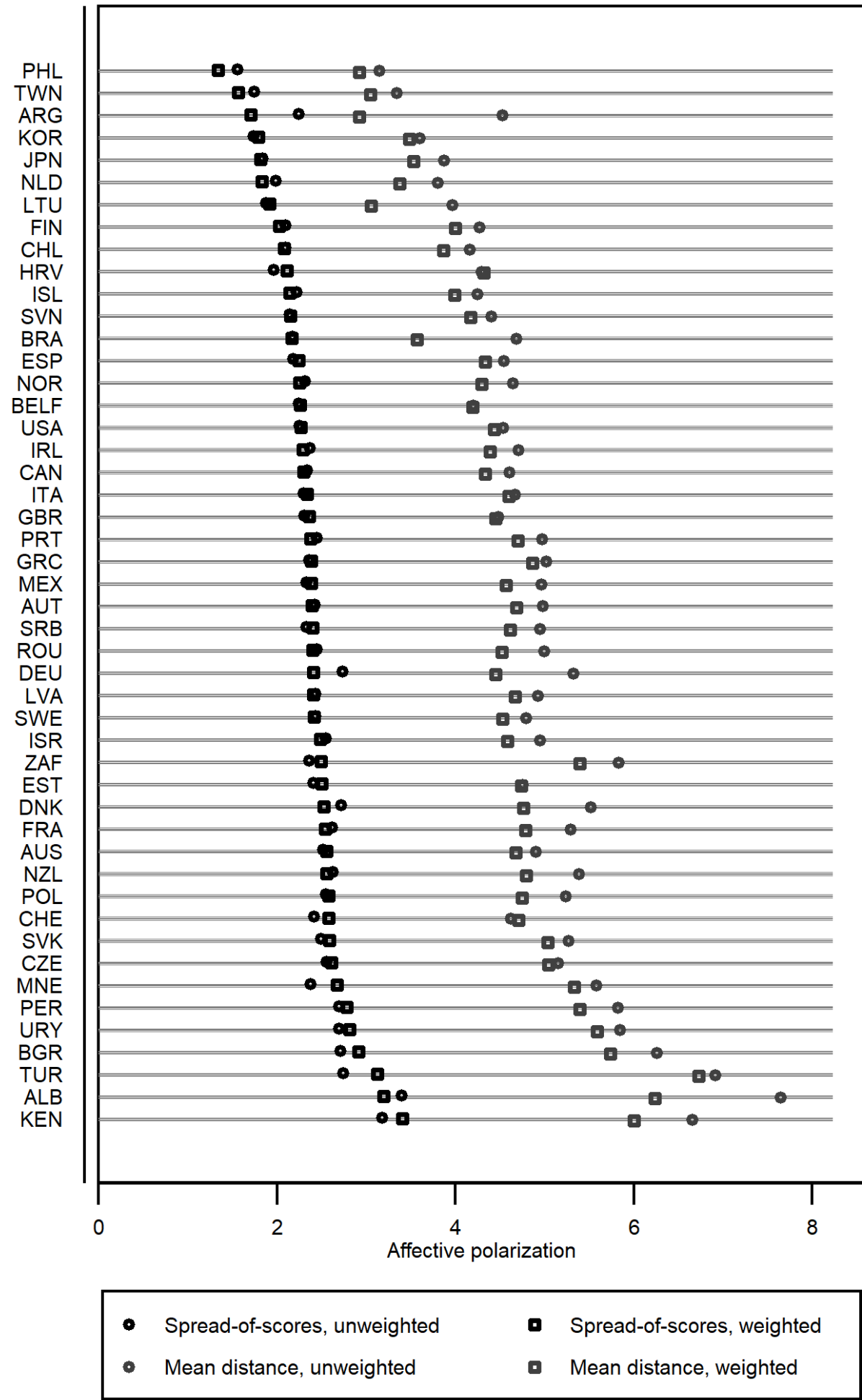




\section{The correlates of affective polarization}

This section's aim is to examine how affective polarization is associated with four other individual-level concepts: positive partisanship, negative partisanship, left-right extremism and perceived left-right party polarization.

This section asks two questions. First, I aim to show that, while affective polarization is correlated with all four individual-level concepts, it goes beyond these. In other words, affective polarization captures something else beyond these concepts. Second, it is important to examine how these correlations depend on the measurement approach. Such variation seems likely, as the mean-distance approach is more linked to partisanship and the spread-of-scores approach more to perceptions of party competition overall.

\section{Affective polarization and partisanship}

Partisanship is likely to increase levels of affective polarization, mainly by increasing negative feelings towards competitors. Positive partisanship may lead citizens to perceive greater differences to other parties (Medeiros and Noël 2014; Greene 1999; Kelly 1989), which will be seen mainly as competitors and rivals (Weisberg 1980). The biased information processing and directional motivated reasoning associated with partisanship may exacerbate such tendencies (Taber and Lodge 2006; Greene 1999; Campbell et al. 1960) Medeiros and Noël (2014) argue that positive partisanship is likely to come before negative feelings about other parties, so it is plausible that dislike of opponents is driven by positive affect for one party rather than vice versa.

However, while partisanship and affective polarization are intrinsically linked concepts, they are not coterminous. For one, partisans vary in the extent they dislike outgroups, as has been shown for the US (Iyengar, Sood and Lelkes 2012). As argued above, affective polarization can also be measured for those without a positive party identification. Indeed, in many European party systems, dislike of an out-party on the radical left or right might be stronger than in-group affect with a favoured party.

This implies that affective polarization captures more than the established concept of partisanship. To examine the extent to which affective polarization and partisanship capture similar phenomena, we can consider differences visible in the CSES data. Partis- 
anship is measured using the standard question included in the CSES: 'Do you usually think of yourself as close to any particular political party??. ${ }^{6}$ It would of course have been useful to be able to use more detailed measures such as that proposed by Bankert, Huddy and Rosema (2017), but these are rarely available in cross-national surveys.

To assess the association between affective polarization and partisanship, I run a series of models with party identification as the outcome variable and each of the measures of affective polarization as the predictor. For these analyses, the measures of affective polarization were standardized to have a mean of 0 and a standard deviation of 1 . These models include fixed effects for each survey (i.e. country-election indicators) to account for time- and country-specific differences in levels of party identification, also relating to how the question is asked in each survey. These models aim to assess associations, not causal relationships.

Figure 2 shows that affective polarization has a clear positive effect on positive partisanship. A standard-deviation increase in affective polarization is associated with about a 15 percent increase in the probability of having a positive party identification. However, this association, while strong, leaves a lot of space for other factors; affective polarization and partisanship are not tautologous concepts.

A similar pattern is present if we take negative partisanship, which is measured exclusively in Round 3 of the CSES. Respondents were asked whether there is a party or candidate they would never vote for. ${ }^{7}$ Figure 2 shows that negative partisanship is more likely for respondents with greater levels of affective polarization, even if the association is clearly smaller than for positive partisanship. Hence, as with positive partisanship, there is a clear link between the concepts of negative partisanship and affective polarization, but the association is not overwhelming.

Figure 2 also allows us to compare how the weighted spread-of-scores measure com-

\footnotetext{
${ }^{6}$ Note that (1) this does not code people who only respond 'yes' to the follow-up question ('Do you feel yourself a little closer to one of the political parties than the others?') as partisans and (2) there is considerable heterogeneity across surveys within the CSES project in terms of the precise questions measuring partisanship.

${ }^{7}$ The precise question is 'And were there any [party or parties/candidate or candidates] that you would never vote for?'
} 
Figure 2: Probability of partisan ID: marginal effect of affective polarization
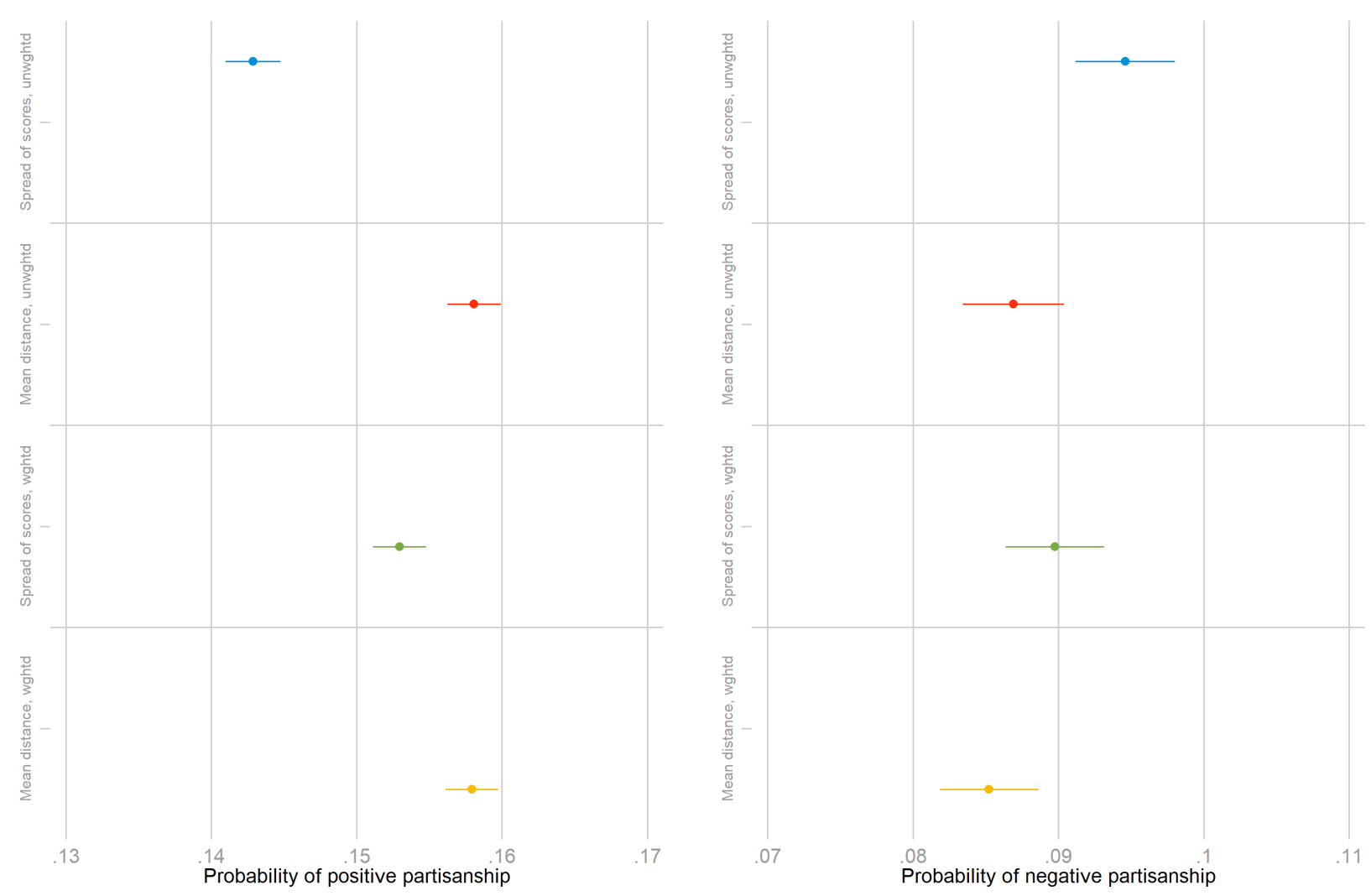

Note: Figure presents the average marginal effect of affective polarization. For calculation of affective polarization measures, refer to text. Country dummies included in model. Left panel: Partisanship measured as a binary variable using the main partisanship question in the CSES, i.e. without the follow-up 'squeeze' question. Analysis uses CSES Modules 1 to 5. Right panel: Negative partisanship measured as 'Is there a party you would never vote for' in CSES Module 3. Full results in Appendix A.2 and A.3. 
pares to the other proposed measures in terms of its association with partisanship. Given its theoretical basis in exclusive social identities, the link between partisanship and the mean-distance approach should be stronger than that between partisanship and the spread-of-scores approach. The former captures whether one party is liked more than others, and this pattern should be related to partisanship. Indeed, Figure 2 shows that the mean-distance measure is somewhat more closely related to partisanship than the spread-of-scores measure, though this difference is not very large.

Interestingly, the spread-of-scores measure is somewhat more closely related to negative partisanship than the mean-distance measure. This indicates that the spread-of-scores measure is better able to capture out-group dislike as a key component of affective polarization. Again, however, the differences between the measures are visible but not very large.

\section{Affective polarization and left-right polarization and ideology}

Affective polarization is associated with, yet distinct from, ideological extremism and polarization (Rogowski and Sutherland 2016; Lelkes 2019; Reiljan 2019; Ward and Tavits 2019). Here, I will examine two phenomena: individual-level ideologial extremism and individual-level perceptions of party system polarization. Again, I will consider the overall association with affective polarization as well as differences between measures.

First, individual extremism summarizes people's political beliefs, which can range from centrist to extreme on a simplified left-right spectrum. Such extremism should be positively associated with affective polarization: the more extreme a citizen is, the more he or she should develop positive and negative feelings towards parties. Westwood et al. (2018) find that partisans distrust those further away ideologically from them the most (see also Lelkes 2019). This association is also indicated by research on negative partisanship, which finds that ideology is a key predictor of negative feelings towards parties (Medeiros and Noël 2014).

The perceived level of ideological polarization between parties should also be associated with affective polarization (Ward and Tavits 2019). Some voters think that many parties stand for more or less the same policies, while others detect large differences in 
party programmes. The more voters think parties are polarized in left-right ideological terms, the more they will see parties as distinct choices and the more they will perceive there to be high stakes associated with electoral outcomes (Rogowski and Sutherland 2016). ${ }^{8}$

I measure (weighted) ideological polarization using a 0-10 left-right scale and the following formula:

$$
\text { Ideologicalpolarization }_{i}=\sqrt{\Sigma_{p=1}^{P} v_{p}\left(\text { position }_{i p}-\overline{\text { position }_{i}}\right)^{2}}
$$

, where position is the left-right position of the party. The mean left-right position should itself be weighted by party size and is calculated as:

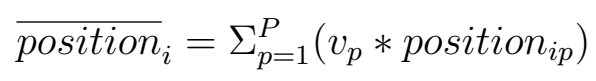

- Figure 3 presents the results of models where the measures of affective polarization are the predictor and ideological polarization the outcome variable; again, survey dummies are included. The Figure shows that there is a clear positive relationship between ideological and affective polarization. Hence, there is unsurprisingly a strong and clear association between the two concepts measured by survey responses. However, the association is not perfect. The effect of a one standard-deviation chagne in each measure in Figure 3 is less than half a standard deviation for ideological polarization. Moreover, the correlation coefficient is just 0.44 for the weighted spread-of-scores measures and 0.41 for the weighted mean-distance measure. So, even though these concept are measured in the same survey in similar ways, they are not that strongly correlated.

The right panel of Figure 3 shows the association between affective polarization and ideological extremism, measured on a 0-5 scale as the distance from the midpoint on the standard 11-point left-right scale. A standard-deviation increase in affective polarization

\footnotetext{
${ }^{8}$ Of course, causality may also run the other way, as affective polarization may affect information seeking and information processing, leading to greater levels of perceived ideological polarization. More simply, affect can lead to assimilation and contrast effects in how survey respondents place political parties (Merrill, Grofman and Adams 2001; Drummond 2011).
} 
is associated with a half-unit increase in ideological extremism.

Figure 3 also indicates how the measures differ in their association with ideological polarization and extremism. We should expect the link between perceived party leftright polarization and the spread-of-scores to be higher, as this measure captures overall divisions within the party system. This is indeed what the left panel of the Figure shows. The right panel shows that all measures are similarly linked to ideological extremism, with the exception of the unweighted spread-of-scores measure.

Figure 3: Affective polarization and Left-Right polarization
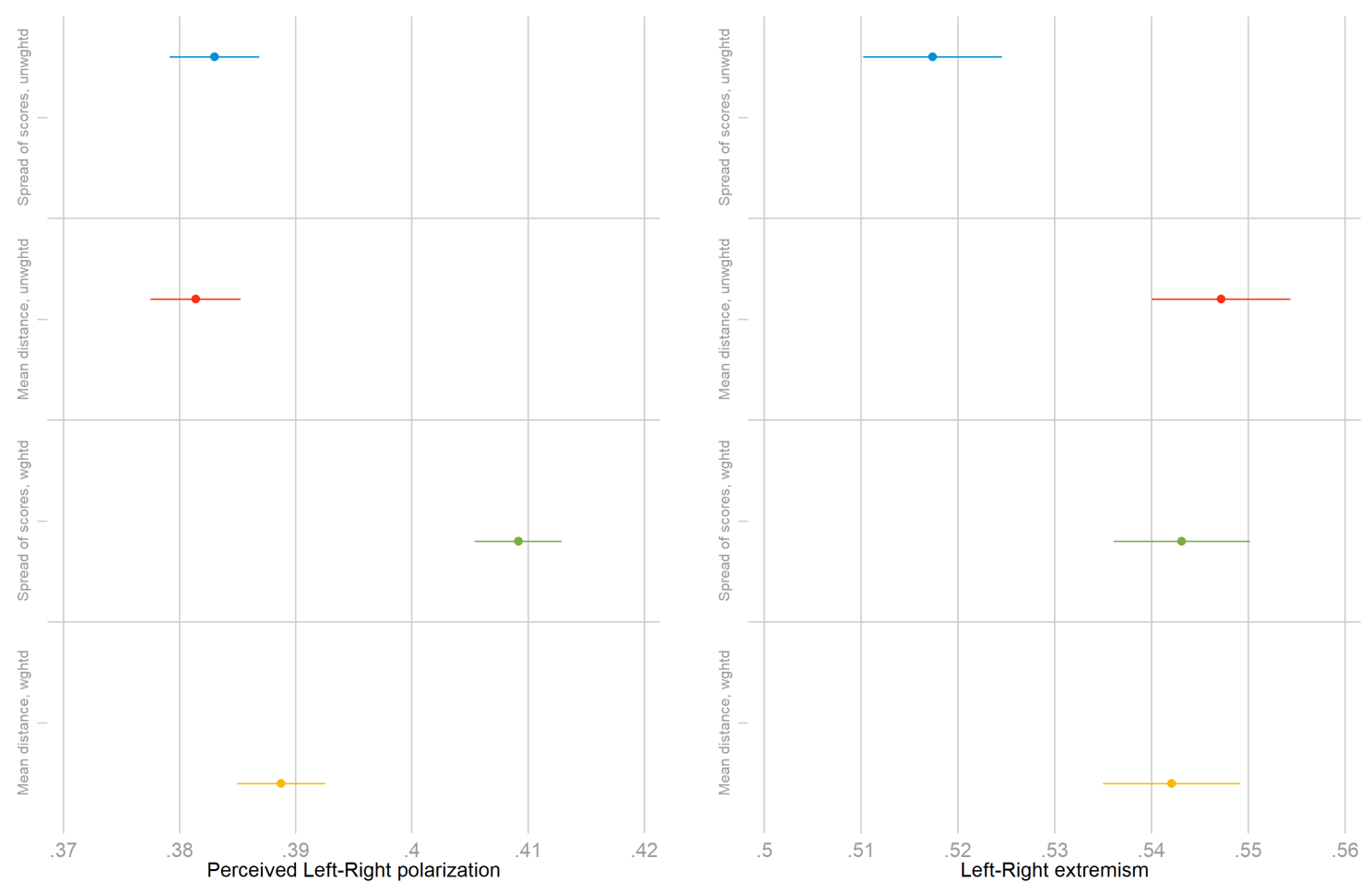

Note: Figure presents the effect of affective polarization. For calculation of affective and ideological polarization measures, refer to text. Country dummies included in model. Left panel: Effect of standardized affective polarization measures of standardized ideological polarization measure. Right panel: Effect of standardized affective polarization measures of Left-Right extremism (range: 0-5). Analyses use CSES Modules 1 to 5. Full results in Appendix A.5 and A.4. 


\section{Association with democratic values and participation}

The aim of this final section is also twofold. First, it assesses whether affective polarization holds any explanatory power for key democratic values and political participation that goes beyond the traditional concepts of partisanship and ideological polarization. Second, this section assesses whether the measures differ in their explanatory power for these outcome variables.

As shown by Ward and Tavits (2019), affective polarization affects perceptions of political choice as well as turnout and participation. This is because strong positive and negative affect towards the parties competing will increase the perception that there is a lot at stake in each election (Ward and Tavits 2019). Moreover, the in-group and outgroup identity-based aspects of affective polarization are likely to increase attention to and engagement with politics (Huddy, Mason and Aarøe 2015). Similarly, Abramowitz and Stone (2006) show that the polarization of evaluations of George W. Bush was an important predictor of turnout and activism as it energizes voters.

This section also assesses whether affective polarization holds explanatory power that goes beyond two key existing variables established in prior research, partisanship and ideological polarization. Existing research on partisanship indicates that it leads to greater engagement in politics (Campbell et al. 1960), higher levels of turnout (Smets and Van Ham 2013) and greater participation in general (Verba, Schlozman and Brady 1995; Rosenstone and Hansen 1993). The relationship between partisanship and satisfaction with democracy is more complex, as 'winners' have higher levels and 'losers' lower levels of satisfaction (Anderson and Guillory 1997; Anderson and Tverdova 2001; Nadeau and Blais 1993; Craig et al. 2006). Existing research on ideological polarization indicates that it leads to higher levels of turnout (Dalton 2008; Crepaz 1990) and greater satisfaction with democracy (Ezrow and Xezonakis 2011), though Rogowski (2014) finds that increased electoral choice leads to lower turnout within the US. Given that affective polarization is related to both partisanship and ideological polarization, we will examine the effects of all three factors below.

The first set of outcome variables are three measures of democratic values. First, I 
examine the standard question on satisfaction with democracy, which has of course been subject to significant criticism (Linde and Ekman 2003; Canache, Mondak and Seligson 2001). This question is measured on a five-point scale. Second, I use a question asking respondents whether they believe that who they vote for makes a difference. Third, I use a question asking respondents whether they believe that it makes a difference who is in power. These two questions have been used in, for instance, Vowles $(2010,2008)$ and Dalton and Anderson (2011)..$^{9}$ The two questions are similar to questions on efficacy as they relate to the belief that citizens can effect political change at the ballot box (Niemi, Craig and Mattei 1991; Campbell, Gurin and Miller 1954).

I run linear regression models predicting each outcome variable. I include fixed effects for each survey. Again, I run models for all measures of affective polarization. I will compare the effects for affective polarization to two other key variables: ideological polarization, measured as described above; and partisanship, included as a dummy variable, with no partisanship as the reference category. I also control for a variable capturing each respondent's the highest like-dislike score, so that affective polarization does not act as a proxy for simply liking a party; this variable can also be seen as an alternative measure of partisanship. Furthermore, I control for standard socio-demographic variables (age, gender, education, income, religiosity and rural-urban residence). Apart from gender, all

\footnotetext{
${ }^{9}$ The precise questions are: 'Some people say that it doesn't make any difference who is in power. Others say that it makes a big difference who is in power. Using the scale on this card, (where ONE means that it doesn't make any difference who is in power and FIVE means that it makes a big difference who is in power), where would you place yourself?' and 'Some people say that no matter who people vote for, it won't make any difference to what happens. Others say that who people vote for can make a big difference to what happens. Using the scale on this card, (where ONE means that voting won't make any difference to what happens and FIVE means that voting can make a big difference), where would you place yourself?'. Note that the exact phrasing of the question has varied slightly across modules.
} 
sociodemographic variables are implemented as continuous variables. ${ }^{10}$ A more substantive control is the left-right extremism of a voter, measured as above on a 0-5 scale.

Figure 4: Affective polarization and democratic values
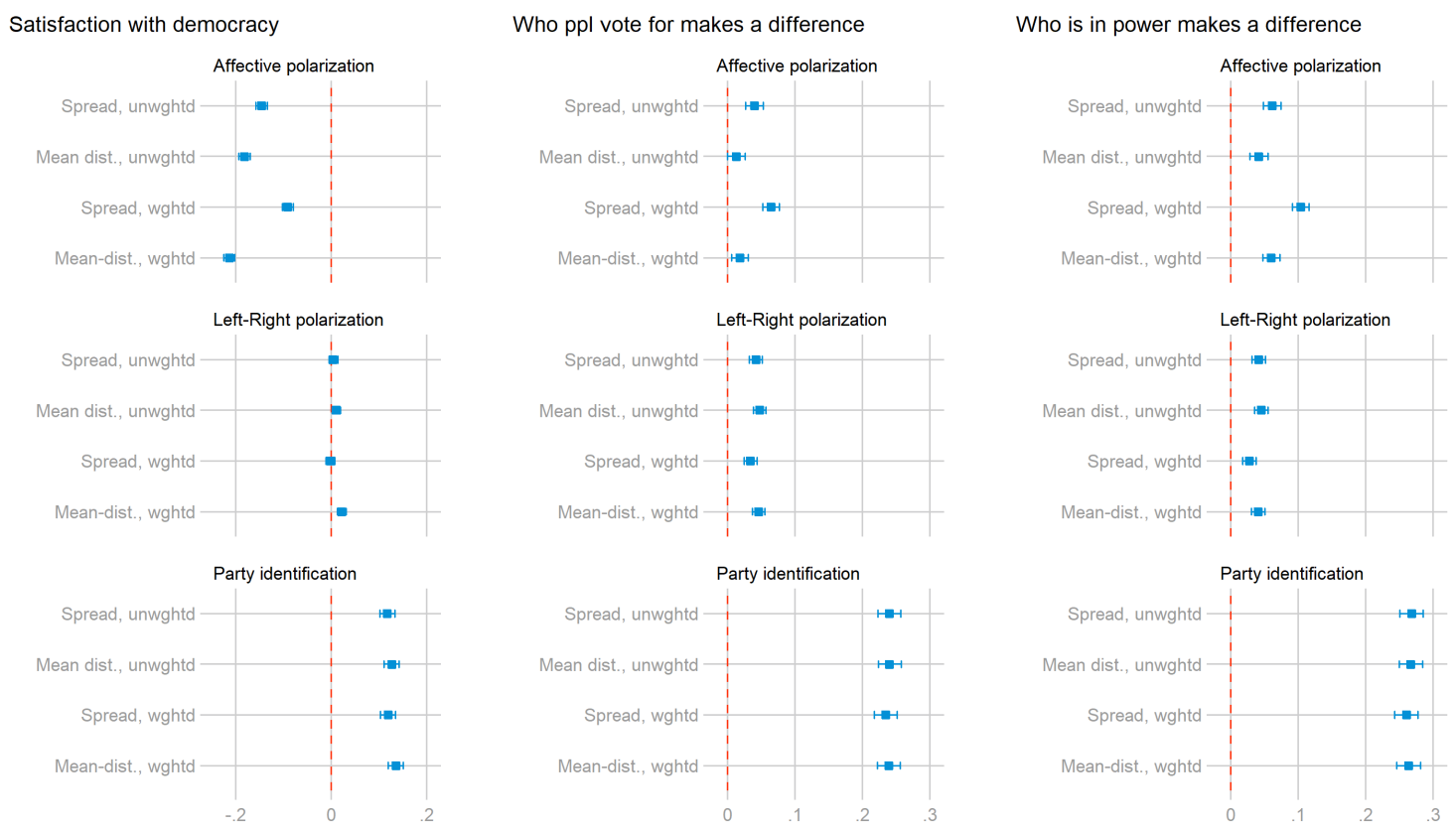

Note: Figure presents the coefficients for affective polarization, ideological polarization and partisanship for four different models, each using a different measure of affective polarization. Each row of coefficients in each panel is a different model. The dependent variables are given at the top of the Figure. For calculation of affective and ideological polarization measures, refer to text. Full models shown in Appendix A.6. Analyses uses CSES Modules 1 to 5 .

The models, presented in Figure 4 and in full in Appendix A.6, show consistent effects for all measures of affective polarization. Each row in the top row of the Figure show the

${ }^{10}$ Age is coded in years; education is coded as none (1), incomplete primary (2), primary completed (3), incomplete primary (4), secondary completed (5), post-secondary completed (6), university undergraduate degree incomplete (7), and university undergraduate degree completed (8); income is coded as the household income in quintiles; religiosiy is coded as: have no religious beliefs (1), not very religious (2), somewhat religious (3), very religious (4); Urban-rural residence is coded as: rural area or village (1), small or middle-sized town (2), suburbs of large town or city (3), large town or city (4). 
effect of affective polarization using each of the four measures. Concerning satisfaction with democracy (left panel), we find that affective polarization leads to a decrease in satisfaction: the more polarized people's interparty hostility, the less they are satisfied with democracy. This is likely to be related to the fact that losing is worse if the opponent is viewed more negatively. However, at the same time affective polarization is associated with believing that it makes a difference who people vote for (middle panel) and who is in power (right panel).

The two bottom rows show the effects of perceived left-right polarization and party identification in each of the four models, i.e. when using different measures of affective polarization. The effects of affective polarization are larger than those for perceived leftright polarization. In contrast, the effect of party identification is larger than that of affective polarization. ${ }^{11}$

The effects also depend somewhat on which measure is used. The spread-of-scores measures has a lower effect on explaining satisfaction with democracy. This is probably because the mean-distance measure captures better whether one single party is liked by respondents. Such respondents may more often be dissatisfied with democratic outcomes, especially if they are on the losing side. In contrast, the spread-of-scores measures has a clearly stronger effect on perceptions of who people vote for and who is in power makes a difference.

Next, we consider two measures of participation. First, we examine self-reported turnout. Second, we use a battery of questions from Round 2 of the CSES project. Here, five activities were asked about: trying to persuade others to vote for a particular party or candidate; showing support for a particular party or candidate by, for example, attending a meeting, putting up a poster, or in some other way; contacting a politician or official; taking part in a protest, march or demonstration; or working together with people who

\footnotetext{
${ }^{11}$ Appendix A.8 presents results for partisans only. The results hold even among partisans: affective polarization has the same type of effects for partisans and non-partisans. That said, the effects of affective polarization are unsurprisingly weaker for partisans: these voters all have a strong identity driving responses to these questions. An interesting question for further study is whether the effect of affective polarization on these attitudes depends on winner-loser status in the political system (Blais and Gélineau 2007).
} 
shared the same concern. To simplify the analysis, I create an index, ranging from 0 to 5 , of the number of activities respondents said they had engaged in in the past five years or so. Both questions are based on self-reported behaviour, which limits their overall validity. However, no alternatives to such questions are available for a broad range of countries.

Figure 5: Affective polarization and participation
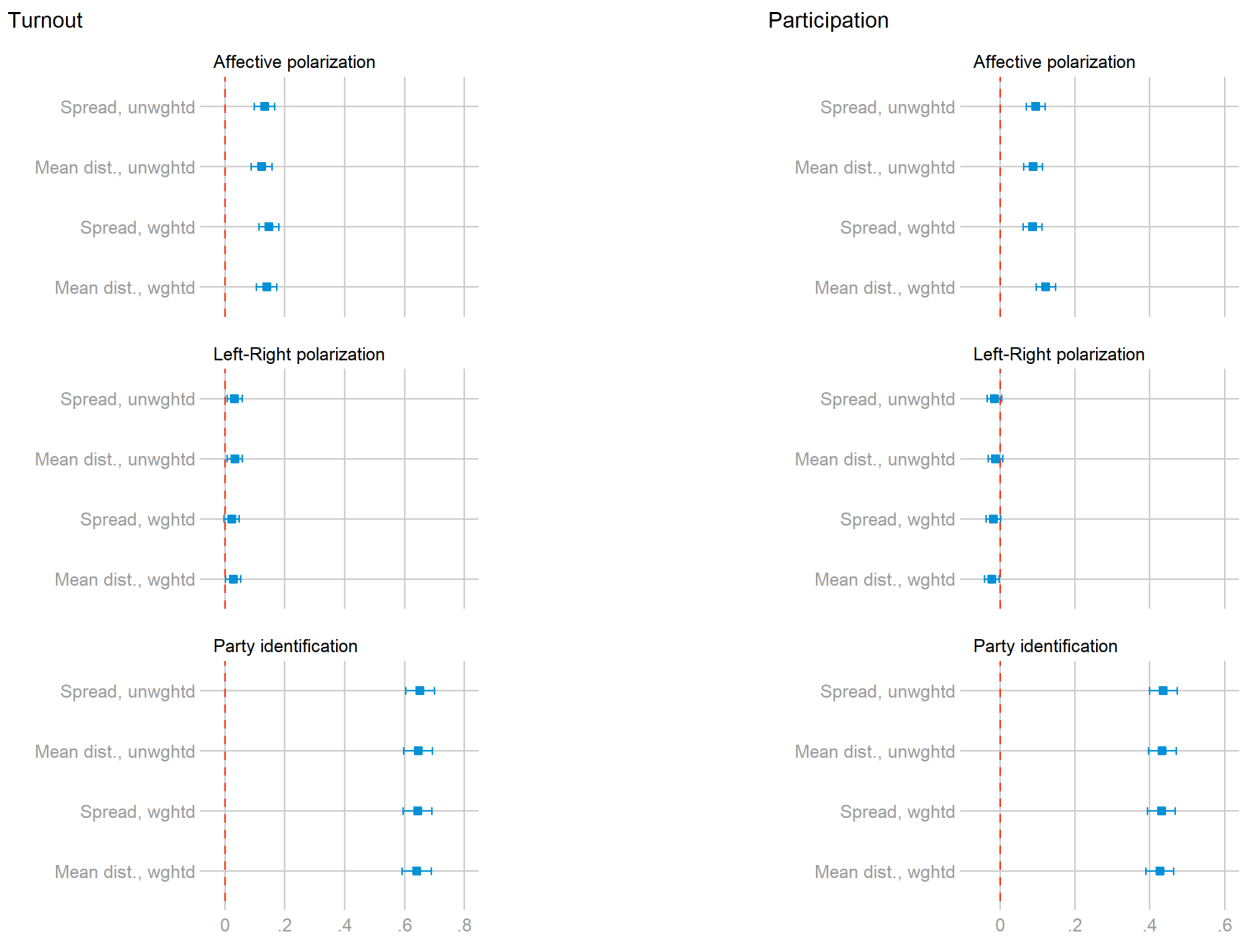

Figure presents the coefficients for affective polarization, ideological polarization and partisanship for four different models, each using a different measure of affective polarization. The dependent variables are given at the top of the Figure. For calculation of affective and ideological polarization measures, refer to text. Full models shown in Appendix A.7. Analyses uses CSES Modules 1 to 5 (left panel) and CSES Module 2 (right panel). Full results in Appendix A.7.

Again, I run regression models with fixed effects for each survey. For voting, I run logistic models; for participation, I run linear models. The controls are the same as in the previous models, though I also control for efficacy (i.e., who is in power and who people vote for makes a difference), as this may impact decisions to participate politically. In 
the models predicting participation, I also control for whether the respondent states that he or she voted or not.

The models, presented in Figure 5 and in full in Appendix A.7, show that affective polarization is consistently associated with a higher likelihood of turning out to vote and with greater participation in politics. Again, the magnitude of these effects is clearer and stronger than for left-right polarization and smaller than for party identification. ${ }^{12}$ Finally, the models show that the measure of affective polarization that we choose does not affect findings for these two outcome variables.

\section{Conclusion}

Applying the concept of affective polarization to multiparty systems requires researchers to adapt approaches to measurement. Moving to multiparty settings means that researchers have to take into account affect across the party system. This creates measurement challenges as researchers need to decide (a) whether to use a single or multiple in-group conceptualization of partisanship and (b) whether the size of parties should matter for affective polarization.

In this paper I have argued that a weighted measure allowing for multiple in-groups is best suited to understanding affective polarization in multiparty systems. This paper has also presented measures that allow researchers to implement their own preferred version of affective polarization using like-dislike scores. Ultimately, the choice of measure depends on the theoretical standpoint of the researcher.

The second contribution of this manuscript has been to apply these measurement approaches to cross-national data from the CSES. The empirical results show that the choice of measure is less consequential than could be expected. Patterns of association do not depend a lot on which measure is used. Empirically, the different measures are highly correlated, mainly because voters do not have one strong in-party.

The analysis of CSES data produces several additional important results. First, the United States, hitherto the focus of most research is not a country with particularly large

${ }^{12}$ Appendix A.8 again shows that the effects for affective polarization also hold for partisans only. 
affective polarization among all citizens (see also Westwood et al. 2018; Gidron, Adams and Horne 2019). Second, affective polarization is linked to positive and negative partisanship as well as ideological polarization, but the findings indicate that these concepts do not fully cover each other. Finally, affective polarization has a stronger association with key measures of citizen engagement with democracy than perceptions of party system polarization. Thus, higher levels of affective polarization are related to higher levels of turnout, participation and perceptions of electoral choice, but lower levels of satisfaction of democracy. Here, affective polarization is associated with these outcome variables in ways that add to existing explanations based on ideological polarization and (positive) partisanship.

Analyzing affective polarization cross-nationally opens up a broad range of potential research questions Gidron, Adams and Horne (2019). Future work should consider explanations for differences in affective polarization over time and across countries. One set of questions concerns the long-term origins of affective polarization. Why do some countries have higher levels of affective polarization than others? Thus, we should investigate how affective polarization is related to, for instance, existing social cleavages (Robison and Moskowitz 2018; Westwood et al. 2018) or economic inequality (Gidron, Adams and Horne 2018). Here, the literature on partisanship and on ideological polarization may provide additional useful starting points (Curini and Hino 2012: e.g.), but this research also needs to take into the unique aspects of affective polarization.

A second set of questions relates to short-term changes in affective polarization. Why does affective polarization increase or decrease from one election to another? How does affective polarization rise and fall depending on context conditions? How does the emergence of radical competitors on the left and right influence affective polarization? Initial findings indicate that affective polarization declines outside of election periods (Hernandez, Anduiza and Rico 2019). Future analyses could provide fresh insights into how to decrease affective polarization (Levendusky 2018; Iyengar et al. 2019; Gidron, Adams and Horne 2019).

Finally, a cross-national study based on post-election surveys can do little to estab- 
lish causality. Researchers should examine how affective polarization causally affects perceived levels of ideological polarization and connections to the democratic system and vice versa. This research should use panel data and experimental designs to test for causal directions in how these attitudes and behaviours are related. 


\section{References}

Abramowitz, Alan I and Steven Webster. 2016. "The rise of negative partisanship and the nationalization of US elections in the 21st century." Electoral Studies 41:12-22.

Abramowitz, Alan I and Walter J Stone. 2006. "The Bush effect: Polarization, turnout, and activism in the 2004 presidential election." Presidential Studies Quarterly $36(2): 141-154$.

Alvarez, R Michael and Jonathan Nagler. 2004. "Party system compactness: Measurement and consequences." Political Analysis 12(1):46-62.

Anderson, Christopher J and Christine A Guillory. 1997. "Political institutions and satisfaction with democracy: A cross-national analysis of consensus and majoritarian systems." American Political Science Review 91(1):66-81.

Anderson, Christopher J and Yuliya V Tverdova. 2001. "Winners, losers, and attitudes about government in contemporary democracies." International Political Science Review 22(4):321-338.

Bankert, Alexa, Leonie Huddy and Martin Rosema. 2017. "Measuring partisanship as a social identity in multi-party systems." Political behavior 39(1):103-132.

Blais, André and François Gélineau. 2007. "Winning, losing and satisfaction with democracy." Political Studies 55(2):425-441.

Boxell, Levi, Matthew Gentzkow and Jesse M Shapiro. 2020. Cross-Country Trends in Affective Polarization. Working Paper 26669 National Bureau of Economic Research.

URL: http://www.nber.org/papers/w26669

Brewer, Marilynn B and Rupert J Brown. 1998. Intergroup relations. McGraw-Hill.

Campbell, Angus, Gerald Gurin and Warren Edward Miller. 1954. "The voter decides.".

Campbell, Angus, Philip Converse, Warren Miller and Donald E Stokes. 1960. "The American Voter." Ann Arbor, MI: University of Michigan Press .

Canache, Damarys, Jeffery J Mondak and Mitchell A Seligson. 2001. "Meaning and measurement in cross-national research on satisfaction with democracy." Public Opinion Quarterly 65(4):506-528.

Carsey, Thomas M and Geoffrey C Layman. 2006. "Changing sides or changing minds? 
Party identification and policy preferences in the American electorate." American Journal of Political Science 50(2):464-477.

Craig, Stephen C, Michael D Martinez, Jason Gainous and James G Kane. 2006. "Winners, losers, and election context: Voter responses to the 2000 presidential election." Political Research Quarterly 59(4):579-592.

Crepaz, Markus ML. 1990. "The impact of party polarization and postmaterialism on voter turnout." European Journal of Political Research 18(2):183-205.

Curini, Luigi and Airo Hino. 2012. "Missing links in party-system polarization: How institutions and voters matter." The Journal of Politics 74(2):460-473.

Dalton, Russell J. 2002. The decline of party identifications. In Parties without partisans, ed. Russel J Dalton and Martin P. Wattenberg. Oxford University Press pp. 19-36.

Dalton, Russell J. 2008. "The quantity and the quality of party systems: Party system polarization, its measurement, and its consequences." Comparative Political Studies 41(7):899-920.

Dalton, Russell J and Christopher J Anderson. 2011. Citizens, context, and choice: how context shapes citizens' electoral choices. Oxford University Press.

Dinas, Elias. 2014a. "Does choice bring loyalty? Electoral participation and the development of party identification." American Journal of Political Science 58(2):449-465.

Dinas, Elias. 2014b. "Why does the apple fall far from the tree? How early political socialization prompts parent-child dissimilarity." British Journal of Political Science $44(4): 827-852$

Druckman, James N and Matthew S Levendusky. 2019. "What Do We Measure When We Measure Affective Polarization?" Public Opinion Quarterly 83(1):114-122.

Drummond, Andrew J. 2011. "Assimilation, contrast and voter projections of parties in left-right space: does the electoral system matter?" Party Politics 17(6):711-743.

Ezrow, Lawrence. 2007. "The variance matters: How party systems represent the preferences of voters." Journal of Politics 69(1):182-192.

Ezrow, Lawrence and Georgios Xezonakis. 2011. "Citizen satisfaction with democracy and parties' policy offerings." Comparative Political Studies 44(9):1152-1178. 
Fiorina, Morris P. 1981. "Retrospective voting in American national elections.".

Garry, John. 2007. "Making 'party identification' more versatile: Operationalising the concept for the multiparty setting." Electoral Studies 26(2):346-358.

Gidron, Noam, James Adams and Will Horne. 2018. How Ideology, Economics and Institutions Shape Affective Polarization in Democratic Polities. In Annual Conference of the American Political Science Association.

Gidron, Noam, James Adams and Will Horne. 2019. "Toward a Comparative Research Agenda on Affective Polarization in Mass Publics." APSA Comparative Politics Newsletter 29:30-36.

Greene, Steven. 1999. "Understanding party identification: A social identity approach." Political Psychology 20(2):393-403.

Greene, Steven. 2004. "Social identity theory and party identification." Social Science Quarterly 85(1):136-153.

Helbling, Marc and Sebastian Jungkunz. 2019. "Social divides in the age of globalization." West European Politics pp. 1-24.

Hernandez, Enrique, Eva Anduiza and Guillem Rico. 2019. Affective polarization and the salience of elections. In Annual Conference of the American Political Science Association.

Hetherington, Marc J and Thomas J Rudolph. 2015. Why Washington won't work: Polarization, political trust, and the governing crisis. University of Chicago Press.

Huddy, Leonie. 2001. "From social to political identity: A critical examination of social identity theory." Political psychology 22(1):127-156.

Huddy, Leonie, Alexa Bankert and Caitlin Davies. 2018. "Expressive versus instrumental partisanship in multiparty european systems." Political Psychology 39:173-199.

Huddy, Leonie, Lilliana Mason and Lene Aarøe. 2015. "Expressive partisanship: Campaign involvement, political emotion, and partisan identity." American Political Science Review 109(1):1-17.

Iyengar, Shanto, Gaurav Sood and Yphtach Lelkes. 2012. "Affect, Not Ideology: A Social Identity Perspective on Polarization." Public opinion quarterly 76(3):405-431. 
Iyengar, Shanto and Sean J Westwood. 2015. "Fear and loathing across party lines: New evidence on group polarization." American Journal of Political Science 59(3):690-707.

Iyengar, Shanto, Yphtach Lelkes, Matthew Levendusky, Neil Malhotra and Sean J Westwood. 2019. "The origins and consequences of affective polarization in the United States." Annual Review of Political Science 22:129-146.

Johnston, Richard. 2006. "Party identification: Unmoved mover or sum of preferences?" Annu. Rev. Polit. Sci. 9:329-351.

Kelly, Caroline. 1989. "Political identity and perceived intragroup homogeneity." British Journal of Social Psychology 28(3):239-250.

Klar, Samara, Yanna Krupnikov and John Barry Ryan. 2018. "Affective polarization or partisan disdain? Untangling a dislike for the opposing party from a dislike of partisanship." Public Opinion Quarterly 82(2):379-390.

Lelkes, Yphtach. 2016. "Mass polarization: Manifestations and measurements." Public Opinion Quarterly 80(S1):392-410.

Lelkes, Yphtach. 2019. "Policy over party: comparing the effects of candidate ideology and party on affective polarization." Political Science Research and Methods pp. 1-8.

Lelkes, Yphtach, Gaurav Sood and Shanto Iyengar. 2017. "The hostile audience: The effect of access to broadband internet on partisan affect." American Journal of Political Science 61(1):5-20.

Lelkes, Yphtach and Sean J Westwood. 2017. "The limits of partisan prejudice." The Journal of Politics 79(2):485-501.

Levendusky, Matthew S. 2018. "Americans, not partisans: Can priming American national identity reduce affective polarization?" The Journal of Politics 80(1):59-70.

Linde, Jonas and Joakim Ekman. 2003. "Satisfaction with democracy: A note on a frequently used indicator in comparative politics." European journal of political research 42(3):391-408.

Maggiotto, Michael A and James E Piereson. 1977. "Partisan identification and electoral choice: The hostility hypothesis." American Journal of Political Science pp. 745-767.

Marcus, George E. 1988. "The structure of emotional response: 1984 presidential can- 
didates." American Political Science Review 82(3):737-761.

Marcus, George E, W Russell Neuman and Michael MacKuen. 2000. Affective intelligence and political judgment. University of Chicago Press.

Mayer, Sabrina Jasmin. 2017. "How negative partisanship affects voting behavior in Europe: Evidence from an analysis of 17 European multi-party systems with proportional voting." Research \& Politics 4(1):2053168016686636.

Medeiros, Mike and Alain Noël. 2014. "The forgotten side of partisanship: negative party identification in four Anglo-American democracies." Comparative Political Studies 47(7):1022-1046.

Merrill, Samuel, Bernard Grofman and James Adams. 2001. "Assimilation and contrast effects in voter projections of party locations: Evidence from Norway, France, and the USA." European Journal of Political Research 40(2):199-221.

Nadeau, Richard and André Blais. 1993. "Accepting the election outcome: the effect of participation on losers' consent." British Journal of Political Science 23(4):553-563.

Niemi, Richard G and M Kent Jennings. 1991. "Issues and inheritance in the formation of party identification." American Journal of Political Science pp. 970-988.

Niemi, Richard G, Stephen C Craig and Franco Mattei. 1991. "Measuring internal political efficacy in the 1988 National Election Study." American Political Science Review 85(4):1407-1413.

Reiljan, Andres. 2019. "Fear and loathing across party lines (also) in Europe: Affective polarisation in European party systems." European Journal of Political Research .

Richardson, Bradley M. 1991. "European party loyalties revisited." American Political Science Review 85(3):751-775.

Robison, Joshua and Rachel Moskowitz. 2018. "The Group Basis of Partisan Affective Polarization." Journal of Politics .

Rogowski, Jon C. 2014. "Electoral choice, ideological conflict, and political participation." American Journal of Political Science 58(2):479-494.

Rogowski, Jon C and Joseph L Sutherland. 2016. "How ideology fuels affective polarization." Political Behavior 38(2):485-508. 
Rose, Richard and William Mishler. 1998. "Negative and positive party identification in post-communist countries." Electoral Studies 17(2):217-234.

Rosenstone, Steven J and John Mark Hansen. 1993. Mobilization, participation, and democracy in America. Macmillan Publishing Company,.

Shively, W Phillips. 1979. "The development of party identification among adults: Exploration of a functional model." American Political Science Review 73(4):1039-1054.

Smets, Kaat and Carolien Van Ham. 2013. "The embarrassment of riches? A metaanalysis of individual-level research on voter turnout." Electoral Studies 32(2):344-359.

Taber, Charles S and Milton Lodge. 2006. "Motivated skepticism in the evaluation of political beliefs." American Journal of Political Science 50(3):755-769.

Verba, Sidney, Kay Lehman Schlozman and Henry E Brady. 1995. Voice and equality: Civic voluntarism in American politics. Harvard University Press.

Vowles, Jack. 2008. "Does globalization affect public perceptions of 'Who in power can make a difference'? Evidence from 40 countries, 1996-2006." Electoral Studies 27(1):6376.

Vowles, Jack. 2010. "Making a difference? Public perceptions of coalition, single-party, and minority governments." Electoral Studies 29(3):370-380.

Ward, Dalston G. and Margit Tavits. 2019. "How partisan affect shapes citizens' perception of the political world." Electoral Studies 60:102045.

Weisberg, Herbert F. 1980. "A multidimensional conceptualization of party identification." Political Behavior 2(1):33-60.

Westwood, Sean J, Shanto Iyengar, Stefaan Walgrave, Rafael Leonisio, Luis Miller and Oliver Strijbis. 2018. "The tie that divides: Cross-national evidence of the primacy of partyism." European Journal of Political Research 57(2):333-354. 


\section{A Appendix}

\section{A.1 Results: conditional bivariate correlations}

This Appendix presents results for how the correlation (Pearson's r) between the different affective polarization measures varies based on two characteristics: the size of the party system and the distance between the most-liked and the second-most-liked party. The size of the party system is measured as the effective number of electoral parties. The Figures present the bivariate correlations for one-unit sets of each variable, so how the correlations change as party system size and the distance from the second-most-liked party increase.

The Figures show that the bivariate correlations do not differ based on the size of the party system; note the narrow range of the y-axis. However, the mean-distance and the spread-ofscores measures diverge for voters who have one clear favoured party, as also indicated by Table 1 in the main paper.

Figure A.1: Bivariate correlation between measures by distance from second-mostliked party
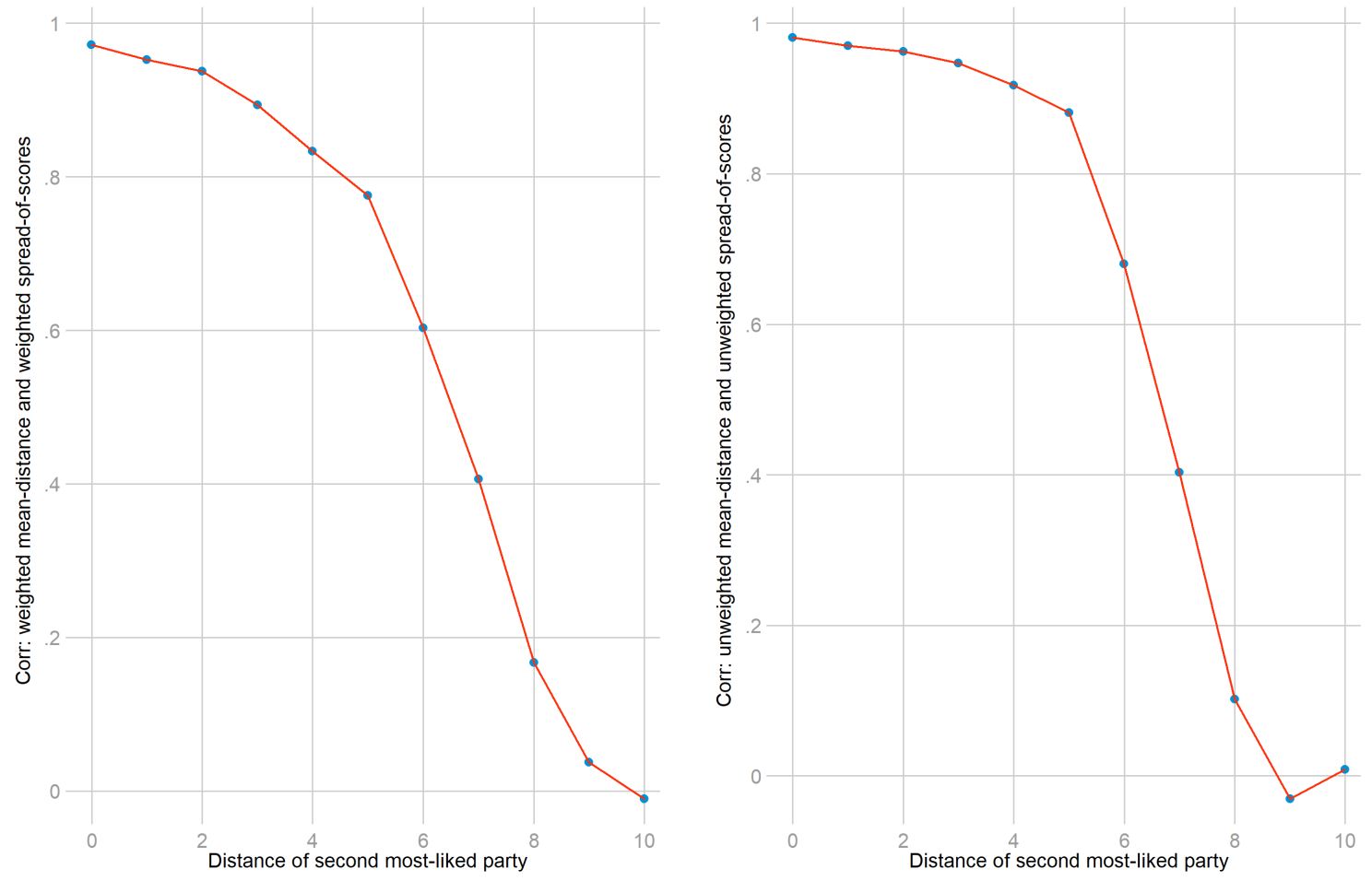
Figure A.2: Bivariate correlation between measures by party system size
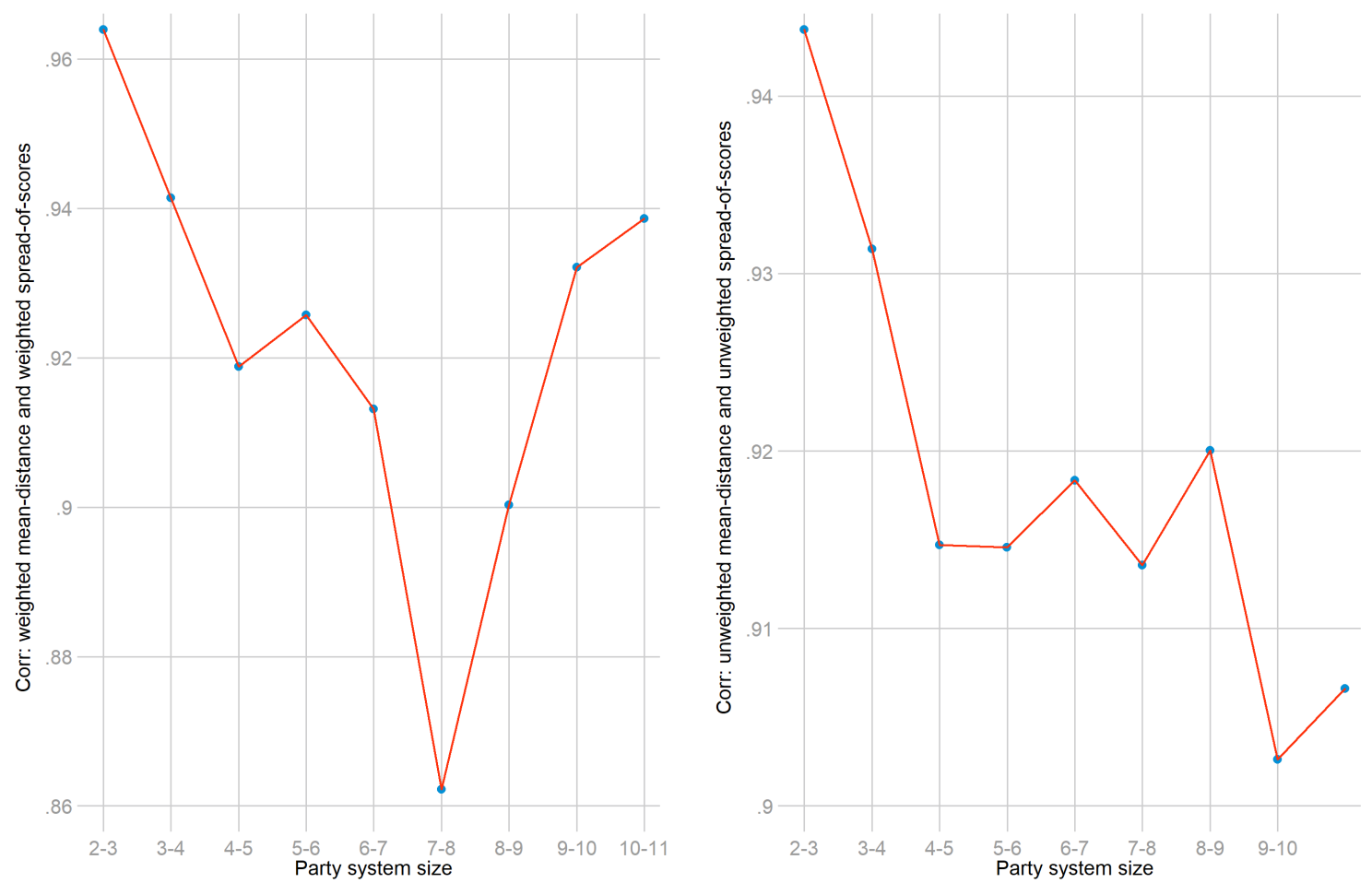

\section{A.2 Results: partisanship}

Note that all regression tables in the Appendix omit the country-survey fixed effects.

Table A.1: Regression table

\begin{tabular}{lcccc}
\hline \hline & $(1)$ & $(2)$ & $(3)$ & $(4)$ \\
& Model 1 & Model 2 & Model 3 & Model 4 \\
\hline Party identification (yes/no) & & & & \\
Aff. Pol. (Mean distance), unweighted & $0.768^{* * *}$ & & & \\
& $(0.00552)$ & & & \\
Aff. Pol. (Spread-of-scores), unweighted & & $0.681^{* * *}$ & & \\
Aff. Pol. (Spread-of-scores), weighted & & $(0.00533)$ & & $0.740^{* * *}$ \\
& & & $(0.00539)$ & \\
Aff. Pol. (Mean distance), weighted & & & & $0.769^{* * *}$ \\
& & & & $0.00546)$ \\
Constant & $-0.393^{* * *}$ & $-0.155^{*}$ & 0.0146 & -0.0453 \\
& $(0.0724)$ & $(0.0697)$ & $(0.0726)$ & $(0.0726)$ \\
\hline Observations & 219867 & 222076 & 219761 & 219761 \\
\hline \hline
\end{tabular}

Standard errors in parentheses

${ }^{*} p<0.05,{ }^{* *} p<0.01,{ }^{* * *} p<0.001$

\section{A.3 Results: negative partisanship}


Table A.2: Regression table

\begin{tabular}{lcccc}
\hline \hline & $\begin{array}{c}(1) \\
\text { Model 1 }\end{array}$ & $\begin{array}{c}(2) \\
\text { Model 2 }\end{array}$ & $\begin{array}{c}(3) \\
\text { Model 3 }\end{array}$ & $\begin{array}{c}(4) \\
\text { Model } 4\end{array}$ \\
\hline nevervote & & & \\
Aff. Pol. (Mean distance), unweighted & $\begin{array}{c}0.59^{* * *} \\
(0.0115)\end{array}$ & & & \\
Aff. Pol. (Spread-of-scores), unweighted & & $0.578^{* * *}$ & & \\
& & $(0.0115)$ & & \\
Aff. Pol. (Spread-of-scores), weighted & & & $0.549^{* * *}$ & $(0.0113)$ \\
Aff. Pol. (Mean distance), weighted & & & & $0.519^{* * *}$ \\
& & & & $(0.0112)$ \\
Constant & $1.059^{* * *}$ & $1.038^{* * *}$ & $0.980^{* * *}$ & $0.995^{* * *}$ \\
& $(0.0585)$ & $(0.0588)$ & $(0.0591)$ & $(0.0587)$ \\
\hline Observations & 56637 & 57113 & 56625 & 56625 \\
\hline \hline
\end{tabular}

Standard errors in parentheses

${ }^{*} p<0.05,{ }^{* *} p<0.01,{ }^{* * *} p<0.001$

\section{A.4 Results: ideological extremism}

Table A.3: Regression table

\begin{tabular}{lcccc}
\hline \hline & $\begin{array}{c}(1) \\
\text { Model 1 }\end{array}$ & $\begin{array}{c}(2) \\
\text { Model 2 }\end{array}$ & $\begin{array}{c}(3) \\
\text { Model 3 }\end{array}$ & $\begin{array}{c}(4) \\
\text { Model } 4\end{array}$ \\
\hline Aff. Pol. (Mean distance), unweighted & $\begin{array}{c}0.547^{* * *} \\
(0.00366)\end{array}$ & & & \\
Aff. Pol. (Spread-of-scores), unweighted & & $\begin{array}{c}0.517^{* * *} \\
(0.00364)\end{array}$ & & \\
Aff. Pol. (Spread-of-scores), weighted & & & $0.543^{* * *}$ & $(0.00359)$ \\
Aff. Pol. (Mean distance), weighted & & & & $0.542^{* * *}$ \\
& & & & $(0.00361)$ \\
Constant & $2.890^{* * *}$ & $3.056^{* * *}$ & $3.157^{* * *}$ & $3.133^{* * *}$ \\
& $(0.0501)$ & $(0.0500)$ & $(0.0499)$ & $(0.0499)$ \\
\hline Observations & 207286 & 208994 & 207187 & 207187 \\
\hline \hline
\end{tabular}

Standard errors in parenthese

${ }^{*} p<0.05,{ }^{* *} p<0.01,{ }^{* * *} p<0.001$

A.5 Results: ideological polarization 
Table A.4: Regression table

\begin{tabular}{|c|c|c|c|c|}
\hline & $\begin{array}{c}(1) \\
\text { Model } 1\end{array}$ & $\begin{array}{c}(2) \\
\text { Model } 2 \\
\end{array}$ & $\begin{array}{c}(3) \\
\text { Model } 3\end{array}$ & $\begin{array}{c}(4) \\
\text { Model } 4\end{array}$ \\
\hline Aff. Pol. (Mean distance), unweighted & $\begin{array}{c}0.381^{* * *} \\
(0.00197)\end{array}$ & & & \\
\hline Aff. Pol. (Spread-of-scores), unweighted & & $\begin{array}{c}0.383^{* * *} \\
(0.00197)\end{array}$ & & \\
\hline Aff. Pol. (Spread-of-scores), weighted & & & $\begin{array}{c}0.409^{* * *} \\
(0.00191)\end{array}$ & \\
\hline Aff. Pol. (Mean distance), weighted & & & & $\begin{array}{l}0.389^{* * *} \\
(0.00194)\end{array}$ \\
\hline Constant & $\begin{array}{c}0.809^{* * *} \\
(0.0279) \\
\end{array}$ & $\begin{array}{c}0.899^{* * *} \\
(0.0277) \\
\end{array}$ & $\begin{array}{r}0.975^{* * *} \\
(0.0274) \\
\end{array}$ & $\begin{array}{c}0.972^{* * *} \\
(0.0277) \\
\end{array}$ \\
\hline Observations & 217661 & 218906 & 217632 & 217632 \\
\hline
\end{tabular}

Standard errors in parentheses

${ }^{*} p<0.05,{ }^{* *} p<0.01,{ }^{* * *} p<0.001$

\section{A.6 Results: democratic values}

Table A.5: Regression table

\begin{tabular}{|c|c|c|c|}
\hline & $\begin{array}{c}\text { (1) } \\
\text { Sat. dem. }\end{array}$ & $\begin{array}{c}(2) \\
\text { Diff who Vote for }\end{array}$ & $\begin{array}{c}(3) \\
\text { Diff who in power }\end{array}$ \\
\hline Aff. Pol. (Spread-of-scores), weighted & $\begin{array}{l}-0.0912^{* * *} \\
(0.00584)\end{array}$ & $\begin{array}{l}0.0649^{* * *} \\
(0.00619)\end{array}$ & $\begin{array}{c}0.104^{* * *} \\
(0.00639)\end{array}$ \\
\hline Left-right polarization, weighted & $\begin{array}{l}-0.00133 \\
(0.00468)\end{array}$ & $\begin{array}{l}0.0341^{* * *} \\
(0.00496)\end{array}$ & $\begin{array}{l}0.0276^{* * *} \\
(0.00511)\end{array}$ \\
\hline Party identification (yes/no) & $\begin{array}{l}0.119^{* * *} \\
(0.00806)\end{array}$ & $\begin{array}{l}0.235^{* * *} \\
(0.00859)\end{array}$ & $\begin{array}{l}0.260^{* * *} \\
(0.00881)\end{array}$ \\
\hline Highest like-dislike score & $\begin{array}{l}0.0983^{* * *} \\
(0.00275)\end{array}$ & $\begin{array}{l}0.0909^{* * *} \\
(0.00293)\end{array}$ & $\begin{array}{l}0.0722^{* * *} \\
(0.00301)\end{array}$ \\
\hline Left-right extremism & $\begin{array}{c}-0.0224^{* * *} \\
(0.00245)\end{array}$ & $\begin{array}{l}0.0297^{* * *} \\
(0.00262)\end{array}$ & $\begin{array}{l}0.0254^{* * *} \\
(0.00268)\end{array}$ \\
\hline Male & $\begin{array}{l}0.0272^{* * *} \\
(0.00735)\end{array}$ & $\begin{array}{l}-0.00242 \\
(0.00783)\end{array}$ & $\begin{array}{l}-0.0130 \\
(0.00804)\end{array}$ \\
\hline Education & $\begin{array}{l}0.0210^{* * * *} \\
(0.00237)\end{array}$ & $\begin{array}{l}0.0399^{* * * *} \\
(0.00251)\end{array}$ & $\begin{array}{l}0.0408^{* * *} \\
(0.00259)\end{array}$ \\
\hline Age & $\begin{array}{c}-0.000684^{* *} \\
(0.000234)\end{array}$ & $\begin{array}{r}-0.0000571 \\
(0.000249)\end{array}$ & $\begin{array}{r}0.000659^{* *} \\
(0.000256)\end{array}$ \\
\hline Income & $\begin{array}{l}0.0527^{* * *} \\
(0.00289)\end{array}$ & $\begin{array}{l}0.0249^{* * *} \\
(0.00309)\end{array}$ & $\begin{array}{l}0.0287^{* * *} \\
(0.00316)\end{array}$ \\
\hline Religiosity & $\begin{array}{l}0.0407^{* * *} \\
(0.00404)\end{array}$ & $\begin{array}{l}0.0381^{* * *} \\
(0.00431)\end{array}$ & $\begin{array}{l}0.0329^{* * *} \\
(0.00443)\end{array}$ \\
\hline Rural-Urban & $\begin{array}{l}-0.0109^{* *} \\
(0.00333)\end{array}$ & $\begin{array}{c}0.00613 \\
(0.00354)\end{array}$ & $\begin{array}{l}0.00797^{*} \\
(0.00364)\end{array}$ \\
\hline Constant & $\begin{array}{l}2.013^{* * *} \\
(0.0481) \\
\end{array}$ & $\begin{array}{l}2.635^{* * *} \\
(0.0508) \\
\end{array}$ & $\begin{array}{l}2.423^{* * *} \\
(0.0526) \\
\end{array}$ \\
\hline Observations & 87109 & 85287 & 88279 \\
\hline
\end{tabular}


Table A.6: Regression table

\begin{tabular}{lccc}
\hline \hline & $(1)$ & $(2)$ & $(3)$ \\
& Sat. dem. & Diff who Vote for & Diff who in power \\
\hline Aff. Pol. (Mean distance), weighted & $-0.213^{* * *}$ & $0.0185^{* *}$ & $0.0602^{* * *}$ \\
Left-right polarization, weighted & $(0.00582)$ & $(0.00622)$ & $(0.00641)$ \\
& $0.0221^{* * *}$ & $0.0463^{* * *}$ & $0.0404^{* * *}$ \\
Party identification (yes/no) & $(0.00459)$ & $(0.00490)$ & $(0.00506)$ \\
& $0.136^{* * *}$ & $0.239^{* * *}$ & $0.264^{* * *}$ \\
Highest like-dislike score & $(0.00802)$ & $(0.00861)$ & $(0.00883)$ \\
& $0.136^{* * *}$ & $0.104^{* * *}$ & $0.0840^{* * *}$ \\
Left-right extremism & $(0.00277)$ & $(0.00298)$ & $(0.00306)$ \\
& $-0.0177^{* * *}$ & $0.0312^{* * *}$ & $0.0267^{* * *}$ \\
Male & $(0.00244)$ & $(0.00262)$ & $(0.00269)$ \\
& $0.0290^{* * *}$ & -0.00321 & -0.0144 \\
Education & $(0.00730)$ & $(0.00783)$ & $(0.00804)$ \\
Age & $0.0206^{* * *}$ & $0.0398^{* * *}$ & $0.0406^{* * *}$ \\
& $(0.00236)$ & $(0.00251)$ & $(0.00259)$ \\
Income & $-0.000500^{*}$ & 0.0000364 & $0.000757^{* *}$ \\
& $(0.000232)$ & $(0.000249)$ & $(0.000256)$ \\
Religiosity & $0.0519^{* * *}$ & $0.0253^{* * *}$ & $0.0293^{* * *}$ \\
Rural-Urban & $(0.00287)$ & $(0.00309)$ & $(0.00317)$ \\
& $0.0355^{* * *}$ & $0.0376^{* * *}$ & $0.0332^{* * *}$ \\
Constant & $(0.00402)$ & $(0.00431)$ & $(0.00444)$ \\
& $-0.00907^{* *}$ & 0.00661 & $0.00836^{*}$ \\
Observations & $(0.00331)$ & $(0.00355)$ & $(0.00365)$ \\
\hline \hline
\end{tabular}

Standard errors in parentheses

${ }^{*} p<0.05,{ }^{* *} p<0.01,{ }^{* * *} p<0.001$

Table A.7: Regression table

\begin{tabular}{lccc}
\hline \hline & $(1)$ & $(2)$ & $(3)$ \\
& Sat. dem. & Diff who Vote for & Diff who in power \\
\hline Aff. Pol. (Spread-of-scores), unweighted & $-0.145^{* * *}$ & $0.0402^{* * *}$ & $0.0615^{* * *}$ \\
& $(0.00613)$ & $(0.00649)$ & $(0.00672)$ \\
Left-right polarization, weighted & 0.00470 & $0.0423^{* * *}$ & $0.0414^{* * *}$ \\
& $(0.00459)$ & $(0.00488)$ & $(0.00504)$ \\
Party identification (yes/no) & $0.118^{* * *}$ & $0.240^{* * *}$ & $0.268^{* * *}$ \\
& $(0.00802)$ & $(0.00857)$ & $(0.00880)$ \\
Highest like-dislike score & $0.115^{* * *}$ & $0.0968^{* * *}$ & $0.0824^{* * *}$ \\
Left-right extremism & $(0.00285)$ & $(0.00303)$ & $(0.00312)$ \\
& $-0.0209^{* * *}$ & $0.0308^{* * *}$ & $0.0274^{* * *}$ \\
Male & $(0.00244)$ & $(0.00262)$ & $(0.00268)$ \\
& $0.0289^{* * *}$ & -0.00424 & -0.0145 \\
Education & $(0.00733)$ & $(0.00782)$ & $(0.00804)$ \\
& $0.0222^{* * *}$ & $0.0394^{* * *}$ & $0.0399^{* * *}$ \\
Age & $(0.00236)$ & $(0.00251)$ & $(0.00259)$ \\
Income & $-0.000604^{* *}$ & 0.0000142 & $0.000790^{* *}$ \\
Religiosity & $(0.000233)$ & $(0.000249)$ & $(0.000256)$ \\
& $0.0527^{* * *}$ & $0.0252^{* * *}$ & $0.0288^{* * *}$ \\
Rural-Urban & $(0.00288)$ & $(0.00309)$ & $(0.00316)$ \\
Constant & $0.0399^{* * *}$ & $0.0376^{* * *}$ & $0.0322^{* * *}$ \\
& $(0.00403)$ & $(0.00431)$ & $(0.00443)$ \\
\hline Observations & $-0.0105^{* *}$ & 0.00642 & $0.00841^{*}$ \\
\hline \hline Standate & $(0.00332)$ & $(0.00354)$ & $(0.00364)$ \\
& $1.918^{* * *}$ & $2.571^{* * *}$ & $2.324^{* * *}$ \\
& $(0.0477)$ & $(0.0505)$ & $(0.0524)$ \\
\hline
\end{tabular}

Standard errors in parentheses

${ }^{*} p<0.05,{ }^{* *} p<0.01,{ }^{* * *} p<0.001$ 
Table A.8: Regression table

\begin{tabular}{lccc}
\hline \hline & $(1)$ & $(2)$ & $(3)$ \\
& Sat. dem. & Diff who Vote for & Diff who in power \\
\hline Aff. Pol. (Mean distance), unweighted & $-0.181^{* * *}$ & $0.0133^{*}$ & $0.0418^{* * *}$ \\
Left-right polarization, weighted & $(0.00615)$ & $(0.00653)$ & $(0.00676)$ \\
& $0.0107^{*}$ & $0.0479^{* * *}$ & $0.0453^{* * *}$ \\
Party identification (yes/no) & $(0.00458)$ & $(0.00488)$ & $(0.00503)$ \\
& $0.127^{* * *}$ & $0.240^{* * *}$ & $0.267^{* * *}$ \\
Highest like-dislike score & $(0.00803)$ & $(0.00860)$ & $(0.00882)$ \\
& $0.129^{* * *}$ & $0.105^{* * *}$ & $0.0889^{* * *}$ \\
Left-right extremism & $(0.00291)$ & $(0.00310)$ & $(0.00319)$ \\
& $-0.0198^{* * *}$ & $0.0314^{* * *}$ & $0.0276^{* * *}$ \\
Male & $(0.00245)$ & $(0.00262)$ & $(0.00269)$ \\
& $0.0311^{* * *}$ & -0.00314 & -0.0149 \\
Education & $(0.00732)$ & $(0.00783)$ & $(0.00805)$ \\
& $0.0207^{* * *}$ & $0.0397^{* * *}$ & $0.0406^{* * *}$ \\
Age & $(0.00236)$ & $(0.00251)$ & $(0.00260)$ \\
Income & $-0.000496^{*}$ & 0.0000354 & $0.000775^{* *}$ \\
& $(0.000233)$ & $(0.000249)$ & $(0.000256)$ \\
Religiosity & $0.0524^{* * *}$ & $0.0251^{* * *}$ & $0.0291^{* * *}$ \\
& $(0.00288)$ & $(0.00309)$ & $(0.00317)$ \\
Rural-Urban & $0.0379^{* * *}$ & $0.0373^{* * *}$ & $0.0324^{* * *}$ \\
& $(0.00403)$ & $(0.00431)$ & $(0.00444)$ \\
Constant & $-0.0102^{* *}$ & 0.00682 & $0.00867^{*}$ \\
& $(0.00332)$ & $(0.00355)$ & $(0.00365)$ \\
\hline Observations & $1.866^{* * *}$ & $2.510^{* * *}$ & $2.264^{* * *}$ \\
\hline \hline Stangan & $(0.0475)$ & $(0.0504)$ & $(0.0523)$ \\
\hline
\end{tabular}

Standard errors in parentheses

${ }^{*} p<0.05,{ }^{* *} p<0.01,{ }^{* * *} p<0.001$

\section{A.7 Results: participation}


Table A.9: Regression table

\begin{tabular}{lcc}
\hline \hline & $(1)$ & $(2)$ \\
& Turnout & Participation \\
\hline \multirow{2}{*}{ Aff. Pol. (Spread-of-scores), weighted } & $0.147^{* * *}$ & $0.0868^{* * *}$ \\
& $(0.0173)$ & $(0.0129)$ \\
Left-right polarization, weighted & 0.0229 & -0.0176 \\
& $(0.0130)$ & $(0.0102)$ \\
Party identification (yes/no) & $0.644^{* * *}$ & $0.431^{* * *}$ \\
Highest like-dislike score & $(0.0246)$ & $(0.0189)$ \\
& $0.110^{* * *}$ & 0.00626 \\
Left-right extremism & $(0.00738)$ & $(0.00642)$ \\
Who vote for makes a diff & 0.0106 & $0.0512^{* * *}$ \\
& $(0.00717)$ & $(0.00570)$ \\
Who in power makes a diff & $0.227^{* * *}$ & $0.0428^{* * *}$ \\
Male & $(0.00950)$ & $(0.00792)$ \\
& $0.0753^{* * *}$ & $0.0422^{* * *}$ \\
Education & $(0.00945)$ & $(0.00759)$ \\
Age & 0.0355 & $0.167^{* * *}$ \\
Income & $(0.0217)$ & $(0.0173)$ \\
& $0.154^{* * *}$ & $0.0889^{* * *}$ \\
Religiosity & $(0.00743)$ & $(0.00553)$ \\
Rural-Urban & $0.0229^{* * *}$ & $-0.00131^{*}$ \\
& $(0.000708)$ & $(0.000560)$ \\
Voted & $0.138^{* * *}$ & $0.0172^{*}$ \\
Constant & $(0.00860)$ & $(0.00683)$ \\
& $0.0668^{* * *}$ & $0.0340^{* * *}$ \\
Observations & $(0.0125)$ & $(0.00988)$ \\
\hline \hline Standard & $-0.0619^{* * *}$ & -0.0122 \\
& $(0.00976)$ & $(0.00778)$ \\
& & $0.168^{* * *}$ \\
& & $(0.0258)$ \\
& $-2.825^{* * *}$ & $0.321^{* * *}$ \\
& $(0.151)$ & $(0.0882)$ \\
\hline & 84109 & 16682 \\
\hline & &
\end{tabular}

Standard errors in parentheses

${ }^{*} p<0.05,{ }^{* *} p<0.01,{ }^{* * *} p<0.001$ 
Table A.10: Regression table

\begin{tabular}{|c|c|c|}
\hline & $\begin{array}{c}(1) \\
\text { Turnout }\end{array}$ & $\begin{array}{c}(2) \\
\text { Participation }\end{array}$ \\
\hline Aff. Pol. (Mean distance), weighted & $\begin{array}{l}0.139^{* * *} \\
(0.0173)\end{array}$ & $\begin{array}{l}0.122^{* * *} \\
(0.0133)\end{array}$ \\
\hline Left-right polarization, weighted & $\begin{array}{l}0.0282^{*} \\
(0.0129)\end{array}$ & $\begin{array}{l}-0.0223^{*} \\
(0.0100)\end{array}$ \\
\hline Party identification (yes/no) & $\begin{array}{c}0.641^{* * *} \\
(0.0247)\end{array}$ & $\begin{array}{l}0.427^{* * *} \\
(0.0189)\end{array}$ \\
\hline Highest like-dislike score & $\begin{array}{c}0.111^{* * *} \\
(0.00746)\end{array}$ & $\begin{array}{l}-0.00401 \\
(0.00649)\end{array}$ \\
\hline Left-right extremism & $\begin{array}{c}0.0105 \\
(0.00718)\end{array}$ & $\begin{array}{l}0.0501^{* * *} \\
(0.00569)\end{array}$ \\
\hline Who vote for makes a diff & $\begin{array}{l}0.228^{* * *} \\
(0.00950)\end{array}$ & $\begin{array}{l}0.0442^{* * *} \\
(0.00791)\end{array}$ \\
\hline Who in power makes a diff & $\begin{array}{r}0.0763^{* * *} \\
(0.00944)\end{array}$ & $\begin{array}{r}0.0418^{* * *} \\
(0.00758)\end{array}$ \\
\hline Male & $\begin{array}{c}0.0331 \\
(0.0217)\end{array}$ & $\begin{array}{c}0.166^{* * *} \\
(0.0173)\end{array}$ \\
\hline Education & $\begin{array}{c}0.154^{* * *} \\
(0.00743)\end{array}$ & $\begin{array}{l}0.0888^{* * *} \\
(0.00552)\end{array}$ \\
\hline Age & $\begin{array}{l}0.0230^{* * *} \\
(0.000708)\end{array}$ & $\begin{array}{l}-0.00138^{*} \\
(0.000560)\end{array}$ \\
\hline Income & $\begin{array}{l}0.139^{* * *} \\
(0.00860)\end{array}$ & $\begin{array}{c}0.0173^{*} \\
(0.00682)\end{array}$ \\
\hline Religiosity & $\begin{array}{c}0.0682^{* * *} \\
(0.0125)\end{array}$ & $\begin{array}{l}0.0356^{* * * *} \\
(0.00987)\end{array}$ \\
\hline Rural-Urban & $\begin{array}{r}-0.0623^{* * *} \\
(0.00976)\end{array}$ & $\begin{array}{c}-0.0125 \\
(0.00777)\end{array}$ \\
\hline Voted & & $\begin{array}{c}0.167^{* * *} \\
(0.0258)\end{array}$ \\
\hline Constant & $\begin{array}{c}-2.862^{* * *} \\
(0.151) \\
\end{array}$ & $\begin{array}{l}0.388^{* * *} \\
(0.0877) \\
\end{array}$ \\
\hline Observations & 84109 & 16682 \\
\hline
\end{tabular}

Standard errors in parentheses

${ }^{*} p<0.05,{ }^{* *} p<0.01,{ }^{* * *} p<0.001$ 
Table A.11: Regression table

\begin{tabular}{lcc}
\hline \hline & $(1)$ & $(2)$ \\
& Turnout & Participation \\
\hline main & & \\
Aff. Pol. (Spread-of-scores), unweighted & $0.133^{* * *}$ & $0.0954^{* * *}$ \\
Left-right polarization, weighted & $(0.0175)$ & $(0.0130)$ \\
& $0.0320^{*}$ & -0.0155 \\
Party identification (yes/no) & $(0.0129)$ & $(0.00996)$ \\
Highest like-dislike score & $0.652^{* * *}$ & $0.436^{* * *}$ \\
& $(0.0246)$ & $(0.0188)$ \\
Left-right extremism & $0.110^{* * *}$ & -0.000810 \\
Who vote for makes a diff & $(0.00762)$ & $(0.00671)$ \\
& 0.0116 & $0.0517^{* * *}$ \\
Who in power makes a diff & $(0.00715)$ & $(0.00567)$ \\
Male & $0.227^{* * *}$ & $0.0435^{* * *}$ \\
& $(0.00948)$ & $(0.00790)$ \\
Education & $0.0761^{* * *}$ & $0.0428^{* * *}$ \\
Age & $(0.00942)$ & $(0.00756)$ \\
& 0.0346 & $0.163^{* * *}$ \\
Income & $(0.0216)$ & $(0.0173)$ \\
& $0.152^{* * *}$ & $0.0877^{* * *}$ \\
Religiosity & $(0.00741)$ & $(0.00552)$ \\
& $0.0230^{* * *}$ & $-0.00129^{*}$ \\
Rural-Urban & $(0.000707)$ & $(0.000559)$ \\
Voted & $0.140^{* * *}$ & $0.0176^{* *}$ \\
Constant & $(0.00858)$ & $(0.00681)$ \\
& $0.0665^{* * *}$ & $0.0329^{* * *}$ \\
Observations & $(0.0124)$ & $(0.00986)$ \\
\hline \hline Standard & $-0.0621^{* * *}$ & -0.0118 \\
& $(0.00974)$ & $(0.00777)$ \\
& & $0.169^{* * *}$ \\
& & $(0.0258)$ \\
& $-2.879^{* * *}$ & $0.341^{* * *}$ \\
& $(0.150)$ & $(0.0882)$ \\
\hline & 84328 & 16735 \\
\hline & &
\end{tabular}

Standard errors in parentheses

${ }^{*} p<0.05,{ }^{* *} p<0.01,{ }^{* * *} p<0.001$ 
Table A.12: Regression table

\begin{tabular}{lcc}
\hline \hline & $(1)$ & $(2)$ \\
& Turnout & Participation \\
\hline Aff. Pol. (Mean distance), unweighted & $0.123^{* * *}$ & $0.0878^{* * *}$ \\
& $(0.0179)$ & $(0.0129)$ \\
Left-right polarization, weighted & $0.0332^{* *}$ & -0.0125 \\
& $(0.0129)$ & $(0.00994)$ \\
Party identification (yes/no) & $0.645^{* * *}$ & $0.433^{* * *}$ \\
Highest like-dislike score & $(0.0246)$ & $(0.0189)$ \\
& $0.113^{* * *}$ & 0.00181 \\
Left-right extremism & $(0.00778)$ & $(0.00677)$ \\
Who vote for makes a diff & 0.0119 & $0.0521^{* * *}$ \\
& $(0.00717)$ & $(0.00568)$ \\
Who in power makes a diff & $0.228^{* * *}$ & $0.0431^{* * *}$ \\
Male & $(0.00950)$ & $(0.00793)$ \\
& $0.0766^{* * *}$ & $0.0439^{* * *}$ \\
Education & $(0.00944)$ & $(0.00758)$ \\
Age & 0.0324 & $0.164^{* * *}$ \\
Income & $(0.0217)$ & $(0.0173)$ \\
& $0.154^{* * *}$ & $0.0882^{* * *}$ \\
Religiosity & $(0.00743)$ & $(0.00553)$ \\
& $0.0230^{* * *}$ & $-0.00138^{*}$ \\
Rural-Urban & $(0.000708)$ & $(0.000561)$ \\
Voted & $0.139^{* * *}$ & $0.0175^{*}$ \\
Constant & $(0.00860)$ & $(0.00683)$ \\
& $0.0675^{* * *}$ & $0.0338^{* * *}$ \\
Observations & $(0.0125)$ & $(0.00988)$ \\
\hline \hline Standar & $-0.0617^{* * *}$ & -0.0123 \\
& $(0.00976)$ & $(0.00779)$ \\
& & $0.169^{* * *}$ \\
& $0.0258)$ \\
& $-2.939^{* * *}$ & $0.304^{* * *}$ \\
& $(0.149)$ & $(0.0873)$ \\
\hline & 84109 & 16679 \\
\hline & &
\end{tabular}

Standard errors in parentheses

${ }^{*} p<0.05,{ }^{* *} p<0.01,{ }^{* * *} p<0.001$ 


\section{A.8 Results for partisans only}

This Appendix presents three key Figures from the paper for those with a party identification only.

Figure A.3: Mean levels of affective polarization by country

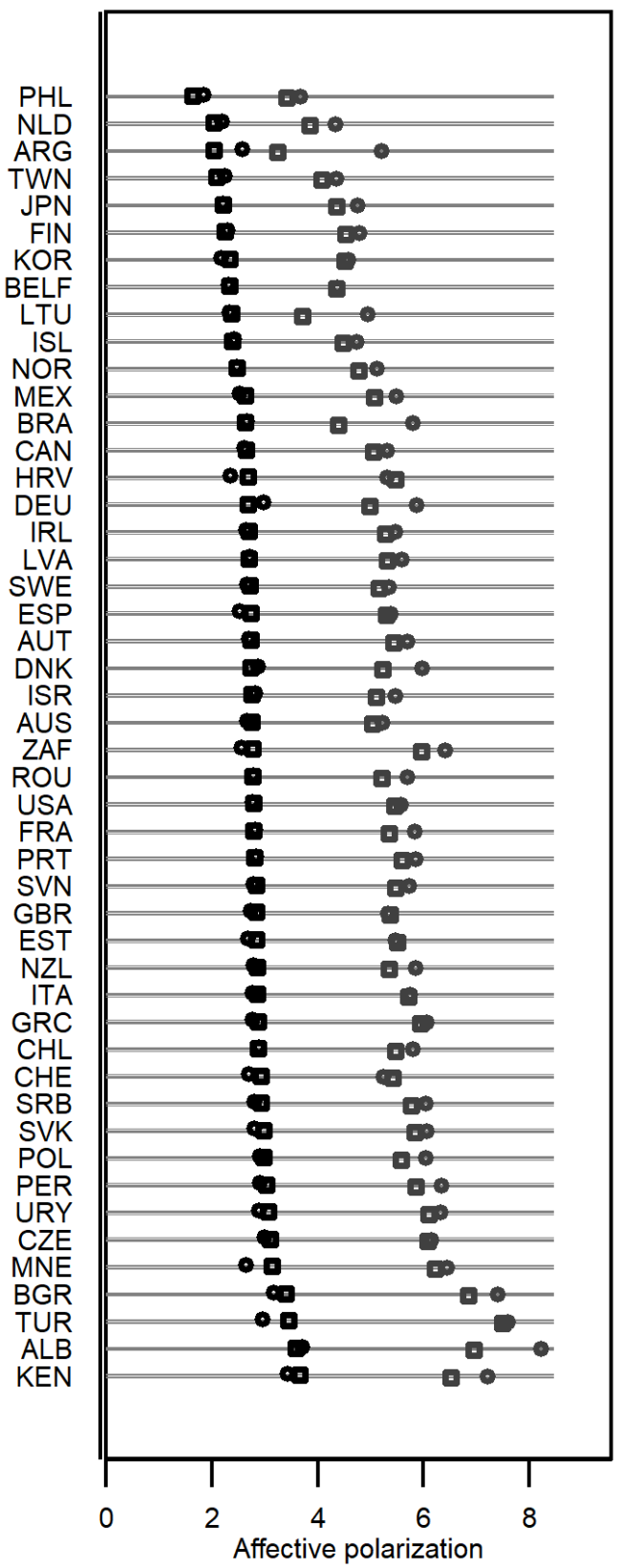

- Spread-of-scores, weighted

- Mean distance, weighted

- Mean distance, unweighted

- Mean distance, weighted 
Figure A.4: Affective polarization and democratic values, partisans only

\section{Satisfaction with democracy}

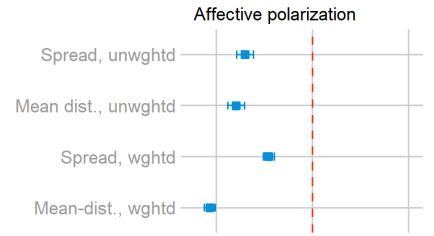

Left-Right polarization
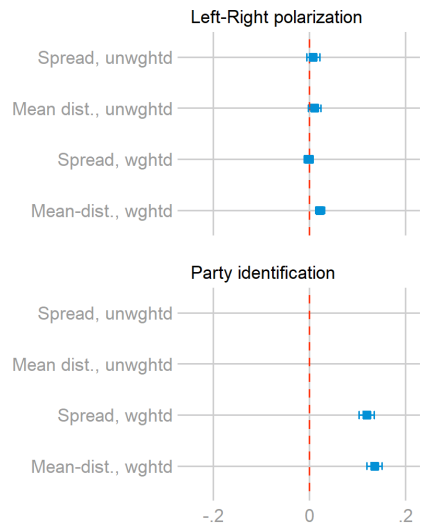

Who ppl vote for makes a difference
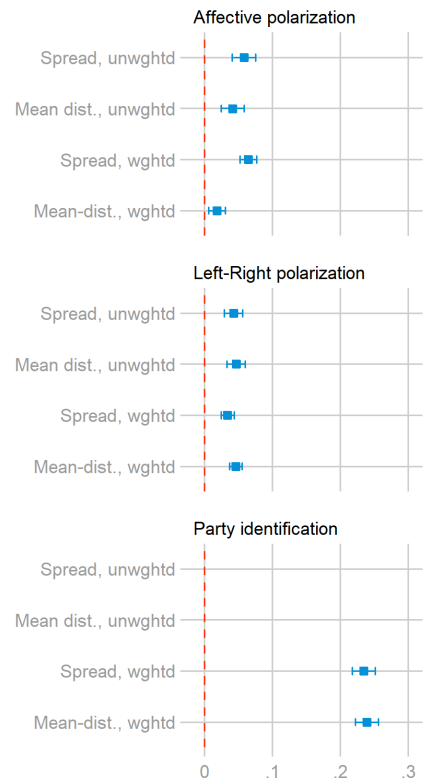

Who is in power makes a difference
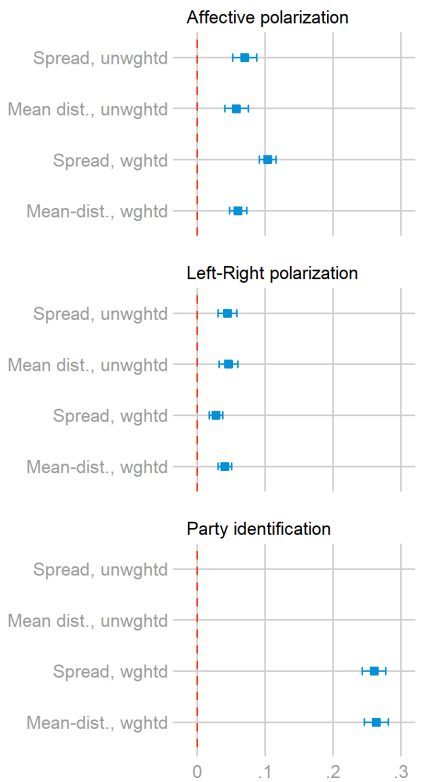

Figure presents the coefficients for affective polarization, ideological polarization and partisanship. For calculation of affective and ideological polarization measures, refer to text. Analyses uses CSES Modules 1 to 5. 
Figure A.5: Affective polarization and participation, partisans only

Turnout
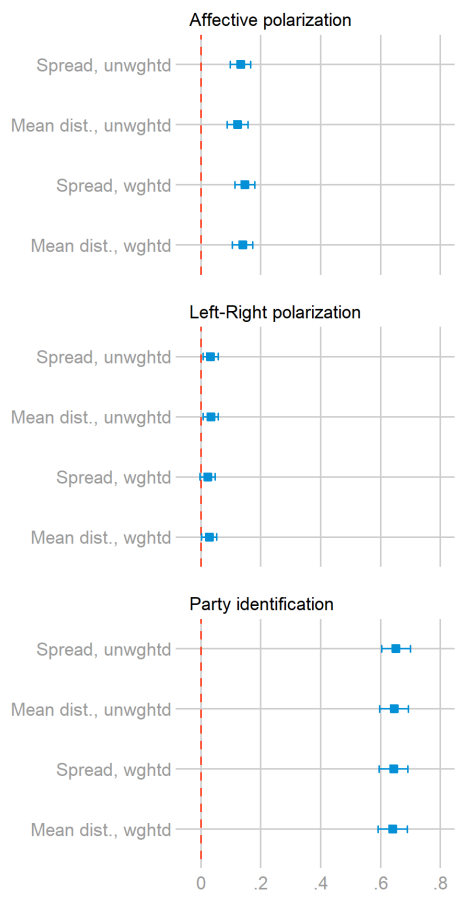

Participation
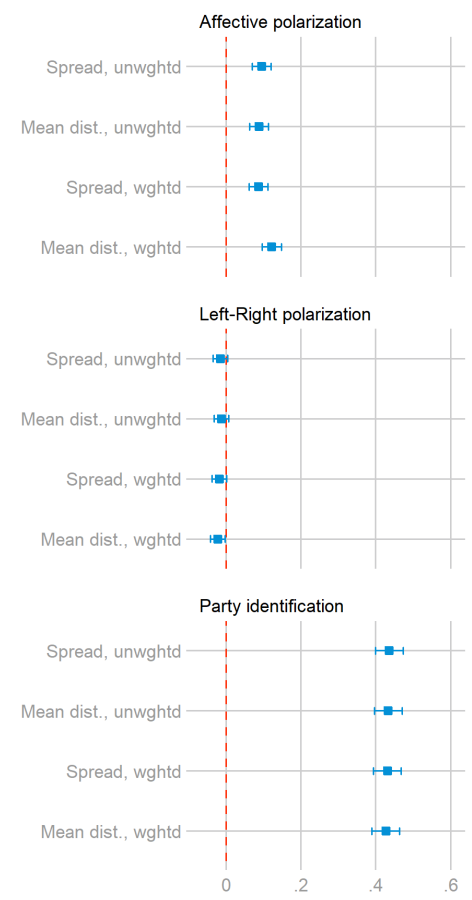

Figure presents the coefficients for affective polarization, ideological polarization and partisanship. For calculation of affective and ideological polarization measures, refer to text. Analyses use CSES Modules 1 to 5 (left panel) and CSES Module 2 (right panel). 